\title{
Baroclinic Instability of the Faroe Bank Channel Overflow*
}

\author{
CHuncheng Guo \\ Geophysical Institute, University of Bergen, and Bjerknes Centre for Climate Research, Bergen, Norway \\ MEHMET ILICAK \\ Uni Research AS, and Bjerknes Centre for Climate Research, Bergen, Norway \\ ILKER FER AND ELIN DARELIUS \\ Geophysical Institute, University of Bergen, and Bjerknes Centre for Climate Research, Bergen, Norway \\ MATS BENTSEN \\ Uni Research AS, and Bjerknes Centre for Climate Research, Bergen, Norway
}

(Manuscript received 11 April 2014, in final form 5 July 2014)

\begin{abstract}
The generation mechanism of mesoscale eddies in the Faroe Bank Channel (FBC) overflow region and their spatiotemporal characteristics are examined using the high-resolution regional Massachusetts Institute of Technology general circulation model $(\mathrm{MITgcm})$. From the modeled overflow, it is found that the volume transport downstream of the FBC sill exhibits strong variability with a distinct period of $\sim 4$ days. Energetic, alternating cyclonic and anticyclonic eddies appear at $\sim 40 \mathrm{~km}$ downstream of the sill. They grow side by side in the nascent stage, but later the cyclones migrate along the $800-\mathrm{m}$ isobath to the south of Iceland, whereas the anticyclones descend downslope across the isobath and gradually dissipate. Analysis of the eddy characteristics shows that the cyclones are associated with a larger plume thickness and width, larger volume transport, colder and denser water, and a plume core located farther downslope, whereas the opposite is true for the anticyclones. The oscillatory structure developed at the lower boundary of the mean plume and the following generation of alternating cyclones and anticyclones are typical features of baroclinic instability. A linear instability analysis of a two-layer analytical baroclinic model yields a most unstable mode that agrees favorably with the simulations. The calculation of the divergent eddy heat flux shows a substantial rightward (upslope)-directed component downstream of the FBC sill. This region is also associated with a strong baroclinic conversion rate. The above arguments constitute evidence for the generation of unstable plume and mesoscale eddies in the FBC region by baroclinic instability.
\end{abstract}

\section{Introduction}

The water exchange between the Nordic Seas and the North Atlantic plays an important role in modulating water mass properties and the thermohaline circulation in the Atlantic. Cold and dense bottom water formed in

\footnotetext{
* Supplemental information related to this paper is available at the Journals Online website: http://dx.doi.org/10.1175/JPO-D-14-0080.s1.

Corresponding author address: Chuncheng Guo, Geophysical Institute, University of Bergen, Alleg. 70, 5007 Bergen, Norway. E-mail: chuncheng.guo@gfi.uib.no
}

high latitudes passes across the Greenland-IcelandScotland Ridge via several pathways and flows into the deep basin. The dense overflow water transforms as a result of vigorous entrainment and mixing as it sinks and eventually contributes to the formation of North Atlantic Deep Water (Dickson and Brown 1994). This water mass exchange is important for understanding the North Atlantic and global climate and has been a topic of numerous studies. For a comprehensive review, readers are referred to Hansen and Østerhus (2000).

The Faroe Bank Channel (FBC) (Fig. 1) is the passage with the second largest volume transport of overflow water from the Nordic Seas to the North Atlantic (after Denmark Strait) and accounts for about one-third of the 


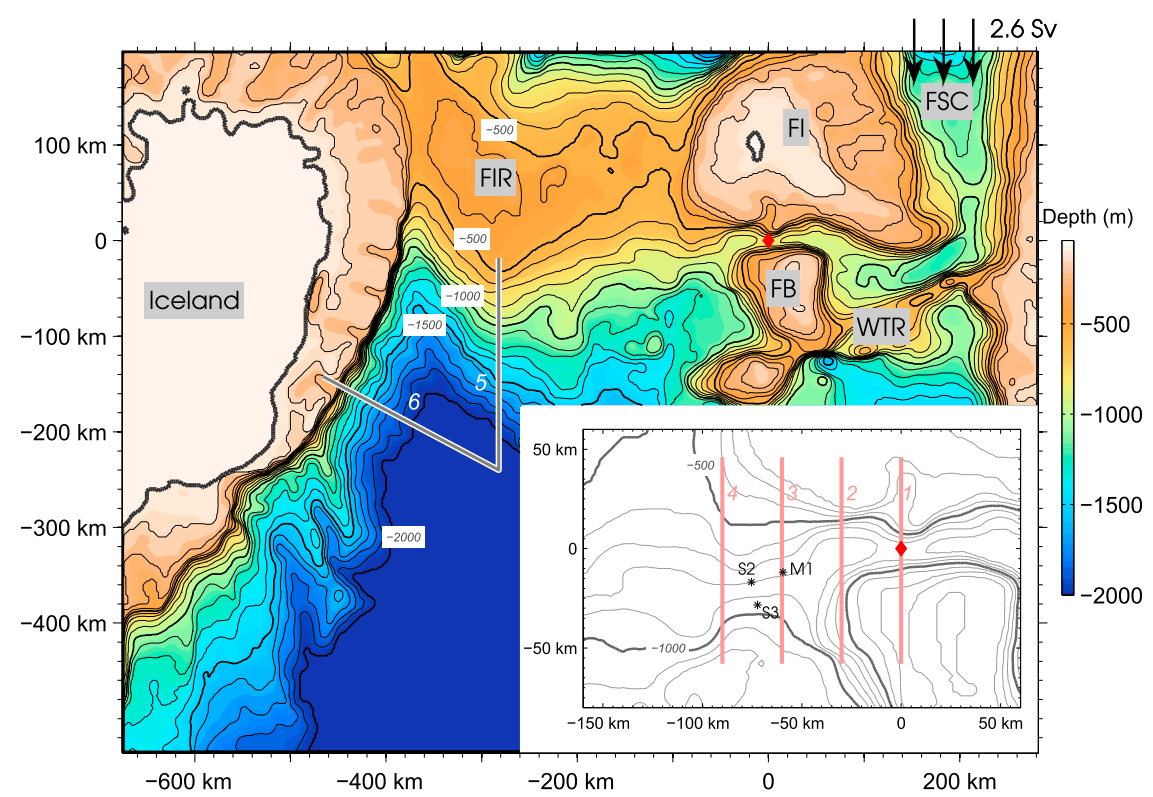

FIG. 1. Bathymetry of the model domain. The contour interval is $100 \mathrm{~m}$. The thick contours indicate the 500-, 1000-, 1500-, and 2000-m isobaths. Dense overflow water enters the domain from the northern boundary with a volume flux of $2.6 \mathrm{~Sv}$, as indicated by the arrows. The red diamond denotes the location of the FBC sill. The inset shows the zoomed-in view of the FBC region, including the locations of the moorings M1, S2, and S3. Six sections labeled with numbers (1-4 shown in the inset) have higher model output frequency $(1 \mathrm{~h})$ and will be used later for analysis. The abbreviations in the figure are Faroe Shetland Channel (FSC), Faroe Island (FI), Faroe Bank (FB), Wyville Thomson Ridge (WTR), and Faroe Iceland Ridge (FIR). Faroe Bank Channel lies in between FI and FB.

total overflow. The cold and dense overflow through the channel has been under intensive observation and monitoring since its discovery (cf. Borenäs and Lundberg 1988; Mauritzen et al. 2005; Hansen and Østerhus 2007; Beaird et al. 2013; and the references therein). The FBC features a narrow channel confined by the Faroe Island to the north and the Faroe Bank to the south, with a $\sim 850$-m-deep sill (Fig. 1). It widens to the Faroe-Iceland slope at approximately $50 \mathrm{~km}$ west of the sill. The dense overflow water from the Norwegian Sea enters the FBC as a bottom-attached gravity current after passing through the Faroe Shetland Channel. It is confined within the FBC and appears to be hydraulically controlled (Borenäs and Lundberg 1988; Girton et al. 2006). The overflow plume spreads as it flows over the sill and descends the widening FBC. During its descent, it is associated with multiple processes such as entrainment, shearinduced mixing, and mesoscale variability (Mauritzen et al. 2005; Fer et al. 2010; Darelius et al. 2011). The plume is consequently diluted and increases in volume transport.

In the FBC, the plume is geostrophically balanced in the cross-channel direction (Hansen and Østerhus 2007; Seim and Fer 2011). This constraint holds along the isobaths as steered by rotation, but can be broken down by bottom friction and baroclinic instability, leading to the generation of energetic eddies and resultant enhanced downslope volume transport (Jiang and Garwood 1995; Tanaka and Akitomo 2001). At the FBC, the plume already exhibits (irregular) oscillations upstream of and above the sill (Darelius et al. 2011; Cuthbertson et al. 2014). Downstream of the sill, strong and regular oscillations of the plume and vigorous eddies are reported from observations (Geyer et al. 2006; Darelius et al. 2011, 2013), numerical simulations (Ezer 2006; Riemenschneider and Legg 2007; Seim et al. 2010), and satellite altimeter data (Høyer and Quadfasel 2001; Darelius et al. 2013). Darelius et al. (2011) reported mesoscale oscillations of the overflow with dominant periods of $2.5-5$ days downstream of the sill in 2-month-long mooring records. Trains of alternating cyclonic and anticyclonic eddies were recorded, in association with changes of plume thickness varying between 100 and $200 \mathrm{~m}$. Observations showed that the oscillations exist throughout the year (Geyer et al. 2006) and in the whole vertical column rather than being bottom intensified (Darelius et al. 2013).

Characteristics of overflow instabilities in a rotating channel can be captured by idealized models (cf. Griffiths et al. 1982; Swaters 1991; Pratt et al. 2008). Griffiths et al. (1982) examined the ageostrophic barotropic instability for a dense overflow with zero potential vorticity. The 
unstable current was explained by the resonant coupling of two waves that are trapped on the two edges of the plume. Swaters (1991) constructed a two-layer model to study the baroclinic evolution of a rotating overflow that intersects sloping topography on the two edges. His results indicated characteristics of baroclinic instability in the plume and amplifying topographic Rossby waves in the upper layer. Unstable perturbations tend to occur near the downslope edge and the instability depends on an interaction parameter that measures the ratio of destabilizing baroclinic vortex stretching to the stabilizing topographic $\beta$ effect. Swaters (1991) model was later refined with the inclusion of a continuously stratified upper layer (Poulin and Swaters 1999; Reszka et al. 2002) that is more realistic. Following these analytical studies, the dynamics and stability of a rotating overflow have been studied in more detail with three-dimensional primitive equation models (e.g., Jiang and Garwood 1995; Jungclaus et al. 2001; Tanaka and Akitomo 2001).

There has been little discussion of the instability characteristics of the FBC overflow. The mechanisms for generation and destabilization of the plume and the subsequent eddies are not understood. Darelius et al. (2011) assessed the possible generation mechanisms such as the commonly seen vortex stretching due to bottom friction and baroclinic instability. They ruled out these two mechanisms due to the mismatch of their observations with some expected features of instability (this will be discussed further in section 7). Rather, Darelius et al. (2011) presented observations that were broadly consistent with the presence of growing topographic Rossby waves in this region. The flow of a dense plume over the slope can support these low-frequency waves with a restoring force resulting from the change of potential vorticity as the plume crosses isobaths, thereby stretching and squeezing the water column.

In contrast with the long-established and continuous observations at the FBC, regional simulations have been lacking. Apart from a few eddy-resolving modeling studies (Ezer 2006; Riemenschneider and Legg 2007; Seim et al. 2010) that addressed the mesoscale variability, modeling-based investigations of the underlying mechanism that governs the unstable plume and the attendant eddies have not been reported. Given the importance of the FBC overflow for the global thermohaline circulation and the incomplete understanding of its dynamics, this work aims to offer a thorough examination of the properties of mesoscale variability and eddies at the Faroe Bank region and identify the controlling mechanism behind them, using a largely numerical approach. Numerical experiments employing a threedimensional regional circulation model with idealized but representative forcing and stratification are used. In addition, some recent field observations and a linear analysis of a baroclinic model of a rotating overflow on a slope (Reszka et al.2002) are used to aid interpretation of the results. It will be shown that the ubiquitous variability observed in the hydrographic and current records is a result of baroclinic instability.

The paper is organized as follows: In section 2, the model setup and observational data are introduced. The modeled mean plume structure is briefly described in section 3. Volume transport associated with the mesoscale variations of the overflow is shown in section 4 , while spatial and temporal characteristics of the mesoscale eddies associated with the unstable overflow are presented in section 5. In section 6, the generation mechanism of the mesoscale variability is addressed. Section 7 discusses baroclinic instability and the influence of varying inflow velocity on the plume dynamics. Conclusions are given in section 8 .

\section{Model setup and observational data}

\section{a. Model setup}

The hydrostatic version of the $z$-level Massachusetts Institute of Technology general circulation model (MITgcm) (Marshall et al. 1997) is employed to perform simulations on an $f$ plane. The model setup is similar to that of Riemenschneider and Legg (2007) but differs in a few aspects, mainly the domain size, the mixing scheme, and the advection scheme for tracers. The model domain is extended farther south and west $(960 \mathrm{~km} \times 736 \mathrm{~km}$; Fig. 1) to minimize the influence of the overflow water at the (closed) southern boundary upon the region downstream of the FBC and to examine the properties of eddies that propagate along the Icelandic coast. The $f$-plane approximation holds as the gravity current crosses the sill and travels westward on the slope. As it flows southward along the Icelandic coast, planetary $\beta$ effects can play some role, but this region is not a focus of the current work. A smoothed and gridded Smith and Sandwell (1997) bathymetry is used and is rotated $45^{\circ}$ counterclockwise from the true north. The runs have a horizontal resolution of $2 \mathrm{~km}$ and a vertical resolution of $100 \mathrm{~m}$ in the upper $400 \mathrm{~m}, 50 \mathrm{~m}$ between 400 and $600 \mathrm{~m}$, and $25 \mathrm{~m}$ below $600 \mathrm{~m}$. There are 64 vertical levels in total. Notice that even with a horizontal resolution of $2 \mathrm{~km}$, the $\mathrm{FBC}$ is resolved only by $7-8$ grid points given its width of $\sim 15 \mathrm{~km}$. The model uses partial step topography to represent the depth levels more accurately.

In contrast to Riemenschneider and Legg (2007), who used zero explicit diffusivity, we use the $K$-profile parameterization (KPP) (Large et al. 1994) for the calculation of 
vertical diffusivity and viscosity in order to account for shear-induced mixing by the dense overflow water. Horizontal diffusivity is set to zero. Horizontal viscosity is calculated by the scale-selective biharmonic Leith (1996) scheme. No-slip conditions are applied at the bottom and side boundaries, and a quadratic drag $\left(C_{d}=\right.$ $\left.2 \times 10^{-3}\right)$ is used. The model employs a third-order direct space-time flux limiter advection scheme for tracers.

The model is driven at the northern boundary of the domain (in the Faroe Shetland Channel; see Fig. 1) by an inflow [2.6 Sverdrups $(\mathrm{Sv}) ; 1 \mathrm{~Sv} \equiv 10^{6} \mathrm{~m}^{3} \mathrm{~s}^{-1}$ ] of dense water $\left(\rho=1028.07 \mathrm{~kg} \mathrm{~m}^{-3}\right)$ below $700 \mathrm{~m}$, which is representative of the observed flow conditions (Riemenschneider and Legg 2007; Mauritzen et al. 2005). An outflow is prescribed in the upper $300 \mathrm{~m}$ of the forcing area to balance the volume of the inflow. The rest of the northern boundary and the boundaries in the east, west, and south are all closed. Wind and tides are not taken into account. In the sensitivity experiments where forcing is varied, only the magnitude of the inflow velocity is changed, but not the density of the inflow water and the area of the forcing region. Above the dense inflow water and inside the model domain, a linear stratification $\left(N^{2}=8.12 \times\right.$ $10^{-7} \mathrm{~s}^{-2}$, where $N$ is the buoyancy frequency) derived from the observations is used (Riemenschneider and Legg 2007). A linear equation of state is applied in the model. A passive tracer $\tau$ with a value of 1 is prescribed for the overflow water at the northern boundary, while for the ambient water $\tau=0$. In the following analysis, a threshold of $\tau=0.1$ is used to define the overflow interface, which yields similar results as using a definition of $\rho=1027.65 \mathrm{~kg} \mathrm{~m}^{-3}$ in the region near the channel (Mauritzen et al. 2005).

The model is spun up for 80 days with a time step of 300 s, after which a steady state near the FBC has been reached. It then produces 8-hourly output between 80 and 110 days. During this period the plume nearly reaches the southern boundary, thus the flow at the FBC region is not affected by the boundary. Higher-frequency output ( $1 \mathrm{~h}$ ) is saved for six sections (see Fig. 1) in order to better examine the variations and temporal evolution of the overflow downstream of the FBC.

\section{b. Observations}

Times series of temperature, salinity, and velocity in the water column were collected near the FBC in the period 28 May 2012 to 5 June 2013. Here we use data from three moorings, S2, S3, and M1 (see Fig. 1 for locations), that were deployed about $70 \mathrm{~km}$ downstream of the FBC sill, in a triangular pattern with $10-20 \mathrm{~km}$ horizontal separation. The moorings were densely instrumented and were equipped with multiple Sea-Bird Electronics temperature recorders (SBE39 and SBE56), conductivity-temperature-pressure recorders (SBE37, Microcats), Anderaa recording current meters (RCM7/ 8), and acoustic Doppler current profilers (ADCPs). The ADCPs were RD Instruments Workhorse 75, 150, or $300 \mathrm{kHz}$, depending on the vertical range that was covered by the mooring. The sampling interval was $15 \mathrm{~s}$ for SBE56, $5 \mathrm{~min}$ for SBE37 and SBE39, 5 to $60 \mathrm{~min}$ for ADCPs with short to long range, and $60 \mathrm{~min}$ for the RCMs. The vertical coverage concentrated on the overflow plume, similar to the measurements of Darelius et al. (2011), but with improved design (less knockdown) and vertical extent to capture all the mesoscale variability. The data from the instruments are corrected for the mooring motion as described in Darelius et al. (2011). Velocity and temperature records are averaged in 1-h bins and interpolated linearly into a uniform height above bottom (hab)-time grid. The data are then low-pass filtered with a 25-h cutoff to remove the tidal and highfrequency variability. Density measurements are not available at comparable vertical resolution; hence, we rely on temperature as a proxy for density. The relationship between temperature and density in the plume is tight (Darelius et al. 2011); water with a temperature of $6^{\circ} \mathrm{C}$ has a potential density of about $1027.67 \mathrm{~kg} \mathrm{~m}^{-3}$, corresponding to the upper part of the plume-ambient interface. To compare with the model results, the volume transport past the mooring of water colder than $6^{\circ} \mathrm{C}$ was calculated. Furthermore, we present the temperature data collected $100 \mathrm{~m}$ above bottom (mab) and use the velocity data from the same level to estimate the relative vorticity, $\xi=\partial v / \partial x-\partial u / \partial y \approx \Delta v / \Delta x-\Delta u / \Delta y$.

\section{Mean plume structure}

Given the similar model configuration to that of Riemenschneider and Legg (2007) and the thorough discussion of the plume structure therein, the mean plume structure is only briefly discussed here. Figure $2 \mathrm{a}$ shows the 30-day-averaged plume thickness and the velocity at $100 \mathrm{mab}$. The dense inflow water enters the FSC from the northern boundary and turns right following the channel. There is a small leakage of dense water across the Wyville Thomson Ridge $(\sim 0.44 \mathrm{~Sv}$, which is consistent with the currently accepted value of $0.3 \mathrm{~Sv}$ ), while the majority of the water flows along the FBC. Upon reaching the narrow and shallow sill, the dense water plunges down the slope with velocities up to $\sim 1 \mathrm{~m} \mathrm{~s}^{-1}$. The overflow plume thins and widens as it sinks, accompanied by strong entrainment and mixing (Riemenschneider and Legg 2007; Fer et al. 2010). The plume thickness drops below $200 \mathrm{~m}$, and the width increases to $\sim 200 \mathrm{~km}$ within $100 \mathrm{~km}$ downstream of the sill. 


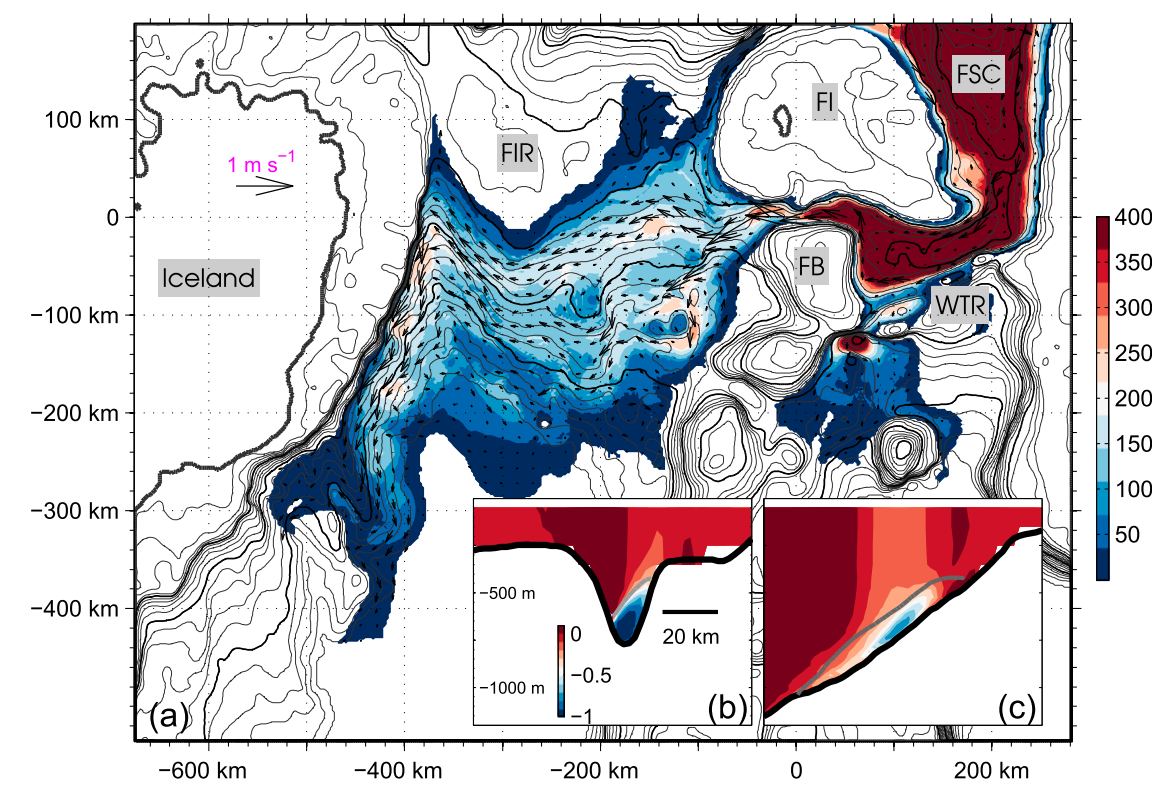

FIG. 2. (a) Distribution of the 30-day mean plume thickness ( $\mathrm{m}$; color) and plume velocity at $100 \mathrm{mab}$ (arrows). (b),(c) The mean zonal velocities across sections 1 and 3 ( $\mathrm{m} \mathrm{s}^{-1}$; color); the gray lines denote the plume interface $(\tau=0.1)$. The $y$ axis, color bar, and the scale shown in (b) also apply to (c).

The mean plume bifurcates into two branches near $x \sim-100 \mathrm{~km}$ in response to a local topographic feature. The northern branch flows predominantly westward following the isobaths (between -500 and $-800 \mathrm{~m}$ ), whereas the southern branch travels southwestward with a cross-isobath component of velocity. Such a bifurcation has been observed by autonomous Seagliders (Beaird et al. 2013). The two branches merge when approaching Iceland and turn sharply southward following the topography. The southward flow is confined above the steep Icelandic continental slope.

Figures $2 \mathrm{~b}$ and $2 \mathrm{c}$ show cross-sectional views of the zonal velocity $u$ seen from the east across section 1 at the sill and section 3 located $60 \mathrm{~km}$ downstream (see Fig. 1 for locations). At the sill section (Fig. 2b), the current leans on the right flank of the channel (looking downstream) and exhibits strong asymmetry, with the thinner plume on the left and the thicker on the right. The mean plume has a maximum thickness of $200 \mathrm{~m}$ and a plumeaveraged velocity of $0.73 \mathrm{~m} \mathrm{~s}^{-1}$. A weak return flow $\left(0.15 \mathrm{~m} \mathrm{~s}^{-1}\right)$ occupies nearly the whole water column on the left flank of the sill (Faroe Bank side). Such a plume structure in a rotating channel is set up by rotation, the pressure gradient, and bottom friction, with the current being geostrophically balanced in the cross-channel direction. The plume thickness and velocity reduce to $140 \mathrm{~m}$ and $0.29 \mathrm{~m} \mathrm{~s}^{-1}$, respectively, at section 3 due to the thinning and widening $(\sim 50 \mathrm{~km})$ of the entraining plume. The current settles on the slope and meanders up and down in association with the translation of eddies. The eddy-associated streamwise transport of the plume will be addressed in the following section.

\section{Transport and eddy regime}

The time-averaged plume structure presented in the previous section smooths out the mesoscale variability. The flow itself destabilizes shortly after passing the sill and the plume appears in instantaneous snapshots as boluses of dense water associated with strong, alternating cyclones and anticyclones. Therefore, the instantaneous plume thickness exhibits distinct patchiness and variation. The eddies generated migrate along the isobaths and can reach the southern boundary of the domain (see the animations described in the appendix that show the time evolution of the plume interface). Mesoscale variability of the overflow is the main scope of this work and will be analyzed in the sections below.

Regular flow oscillations already exist above and upstream of the sill, as reported from observations (Hansen and Østerhus 2007; Darelius et al. 2011) and modeling studies (Cuthbertson et al. 2014). The oscillations in volume transport amplify with increasing downstream distance. Time series of the volume transport for a 30-day period are shown in Fig. 3 for sections 1 to 4. Because of the strong entrainment and mixing that occur with the descending of the overflow, the mean transport continuously increases downstream of the sill (see the mean 


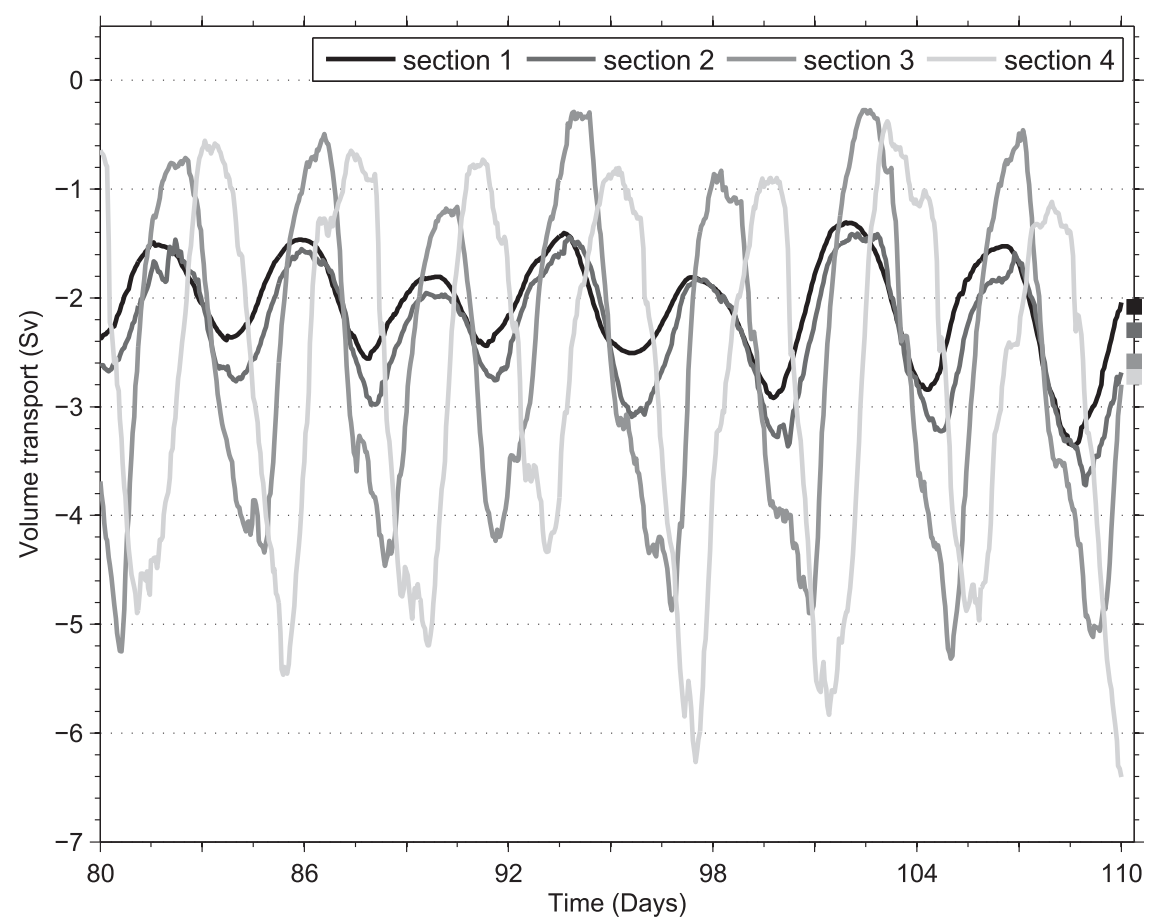

FIG. 3. Time series of volume transport across sections $1-4$. Recall that section 1 is above the sill, whereas sections 2,3 , and 4 are 30,60 , and $90 \mathrm{~km}$ west of the sill, respectively. The colorcoded squares on the right denote the 30 -day mean values for the four sections.

values as indicated by the squares in Fig. 3). The most abrupt increase takes place between sections 2 and 3, suggesting that this region accounts for most of the entrainment. During strong transport periods, the transport increases monotonically from section 1 to 4 , whereas during weak periods the transport is lower at sections 3 and 4 than at sections 1 and 2. Following the method of Riemenschneider and Legg (2007) for the calculation of a bulk entrainment coefficient $\alpha_{E}$ [see Eqs. (7)-(9) in their paper] that estimates the change of overflow volume transport in and out of a given region, $\alpha_{E}=3.6 \times 10^{-4}$ is obtained for the region confined within $x=[-100,0] \mathrm{km}$ and $y=[-50,50] \mathrm{km}$ where most entrainment occurs downstream of the sill. This is close to that estimated by Riemenschneider and Legg (2007) $\left(\alpha_{E} \sim 3-5 \times 10^{-4}\right)$. However, no explicit diffusivity was used in their model, whereas in the current setup the KPP scheme that accounts for vertical mixing is employed, which can lead to a difference in calculating $\alpha_{E}$.

Spectral analysis shows that the time variability at sections $1-4$ has a uniform dominant period of $\sim 4$ days, consistent with mooring observations in this region (Darelius et al. 2011). Overflow-induced mesoscale cyclones and anticyclones emerge approximately $30 \mathrm{~km}$ downstream of the sill. Figure 4 shows a Hovmöller diagram of the overflow volume transport downstream of the sill in which strong pulses can be clearly identified from $\sim 30 \mathrm{~km}$ downstream. These eddy-induced pulses build up and reach a maximum near sections 3 and 4; then they gradually weaken as the plume flows along the slope. The simulation results are consistent with the eddy regime identified by Cenedese et al. (2004) and Ezer (2006). The variability weakens by the time the plume reaches section 5, where no distinct period can be inferred.

The appearance of eddies from $x=30-40 \mathrm{~km}$ downstream is consistent with the analytical stability analysis of a hydraulically driven sill flow in a rotating parabolic channel (Pratt et al. 2008). A dimensionless parameter $\kappa$, defined as $\kappa=2 \alpha g^{\prime} / f^{2}$, was found to play a decisive role in the stability of overflow and its subsequent nonlinear evolution. Here $f$ is the Coriolis parameter, $\alpha$ is the parameter that determines the parabolic shape of the channel [in the form $h(y)=\alpha y^{2}$ ], and $g^{\prime}=g \Delta \rho / \rho_{0}$ is the reduced gravity where $g$ is the acceleration due to gravity, $\Delta \rho$ is the density difference in a two-layer system, and $\rho_{0}$ is a reference density. The overflow is unstable for finite $\kappa$; and small positive $\kappa$ (dynamically wider channels) is associated with strong instability and is accompanied by the generation of eddies (with a threshold of $\sim 0.08$ ), whereas instability decreases as $\kappa$ increases (dynamically narrower channel). Pratt et al. (2008) also examined the instability of a hydraulically controlled flow over a sill and into an open deep basin 


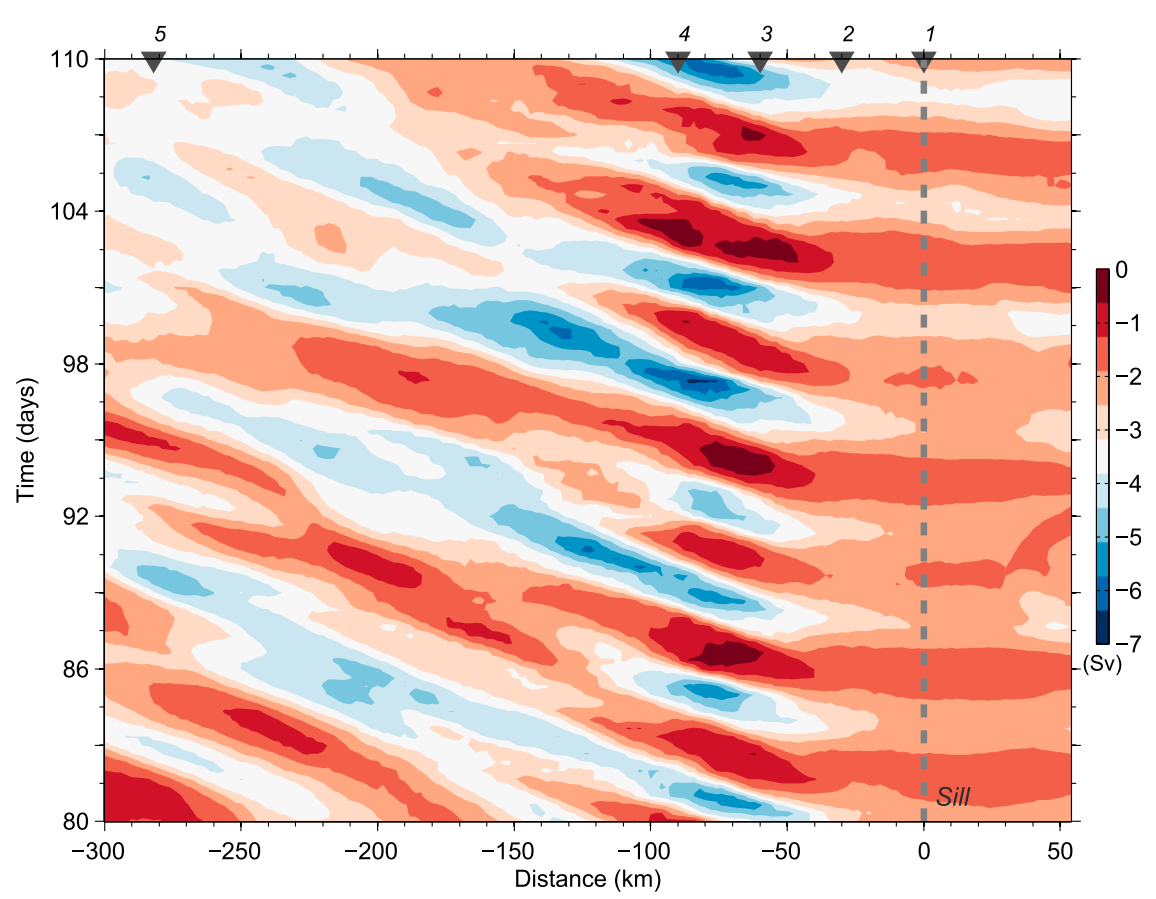

FIG. 4. Hovmöller diagram of the overflow volume transport (Sv) downstream of the sill. The dashed line denotes the location of the sill. Five triangles denote the locations of sections $1-5$.

and found that with an upstream channel curvature of $\kappa=0.4$, no eddies appear when the downstream channel has the same curvature, but they do appear when downstream channel curvature is reduced to below 0.08 .

Given the close similarity of Pratt et al. (2008)'s model configuration with the FBC, the values of $\kappa$ are calculated from $x=50$ to $-100 \mathrm{~km}$ downstream by parabolic fit with the meridional cross-sectional topographies (using $g^{\prime}=4.3 \times 10^{-3} \mathrm{~m} \mathrm{~s}^{-2}$ ). The channel is narrowest near the sill and then widens downstream. Consequently, the calculated $\kappa$, with a value of $\sim 0.7$ upstream, increases to $\sim 1.6$ near the sill and then drops drastically to $\sim 0.05$ at $x \sim-40 \mathrm{~km}$ (figure not shown). After passing over the sill, the most abrupt drop occurs between $x=$ -30 and $-40 \mathrm{~km}$, which coincides with the position in the simulation where eddies develop, highlighting the significance of topographic control on the generation of instability and eddies in the FBC region.

\section{Spatiotemporal characteristics of the eddies}

The discussion in the previous section suggests strong eddy activity downstream of the sill. In this section, spatial features of the eddies and their time evolution are examined in more detail.

Figures 5 and 6 show two snapshots $(t=90.33$ and 92.33 days) of the surface and bottom-averaged scaled relative vorticity $\xi / f$ and the velocity field. The averaging at the bottom is done between $50 \mathrm{~m}$ above and $50 \mathrm{~m}$ below the plume interface (defined as $\tau=0.1$ ). The two figures are representative of the initial phase of eddy evolution. Three eddies are present at $t=90.33$ days (Fig. 5), including two cyclones ( $\mathrm{C} 1$ and $\mathrm{C} 2$ ) and one anticyclone (AC1). C2 is located near $x=-40 \mathrm{~km}$ and is in the nascent stage of development. The eddies are vertically aligned, with their bottom and surface signatures situated at approximately the same location. The eddy features on the surface are apparently caused by the unstable descending overflow. The overflow plume thus has a surface signature that is consistent with barotropic features seen in both satellite and in situ observations (Høyer and Quadfasel 2001; Darelius et al. 2013). The generation mechanism of the eddies is the topic of the next section.

Two days later at $t=92.33$ days (Fig. 6), the three eddies move westward and exhibit meandering patterns. $\mathrm{C} 1$ propagated westward along the $800-\mathrm{m}$ isobath in a coherent manner, whereas AC1 has slumped across the slope and descended to $\sim 1000-\mathrm{m}$ depth. Meanwhile, $\mathrm{C} 2$ is at the mature stage and also follows the $800-\mathrm{m}$ isobath. Tanaka and Akitomo (2001) also reported downslope migration of anticyclones in their idealized numerical simulation of baroclinic instability of a density current flowing along a sloping bottom.

Figure 7 shows the time evolution of the surface and bottom-averaged $\xi / f$ along section 3, together with the meridional extent and volume transport of the plume. 


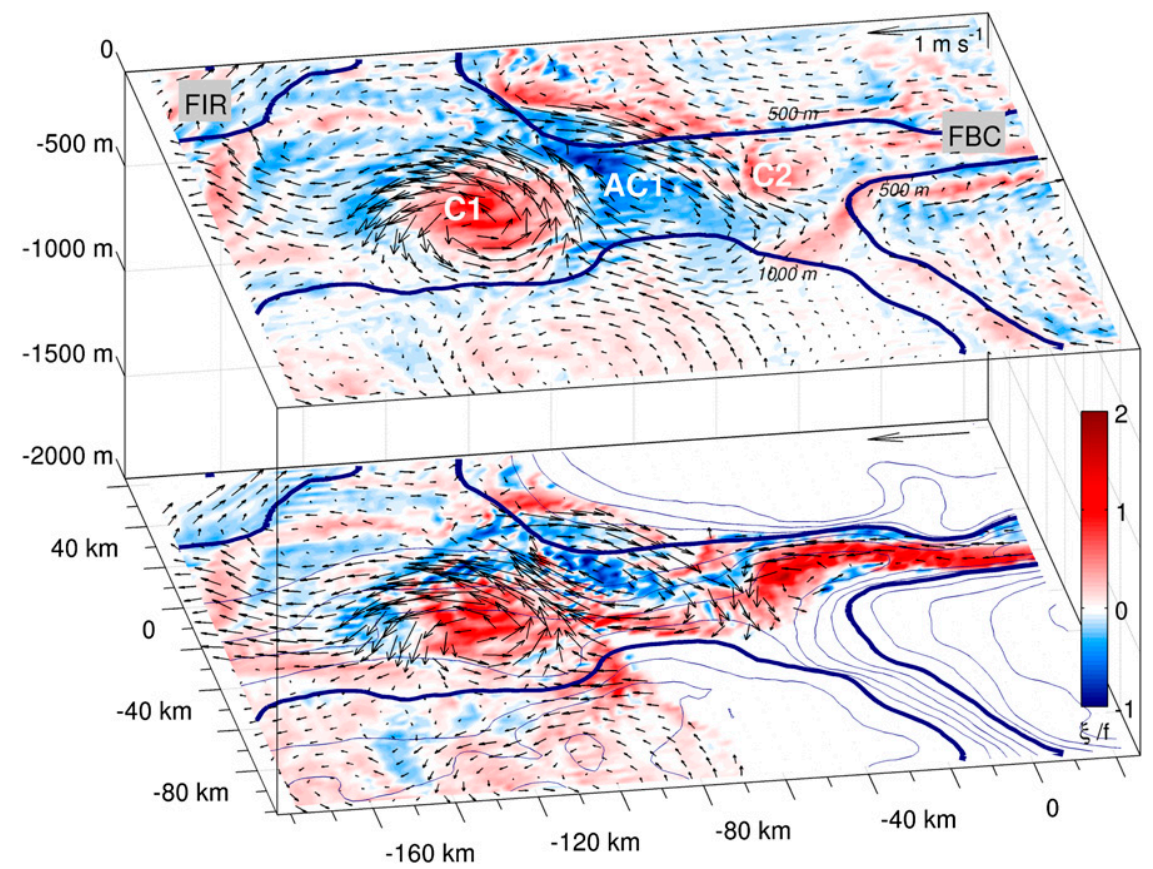

FIG. 5. Horizontal sections for surface- and bottom-averaged scaled relative vorticity ( $\xi / f$; color) and velocity field (arrows) at $t=90.33$ days. Overlain contours are isobaths with an interval of $100 \mathrm{~m}$ in the lower slice and of $500 \mathrm{~m}$ in the upper slice. Labeled $\mathrm{C} 1$ and $\mathrm{C} 2$ denote two cyclones, and AC1 denotes an anticyclone.

As in Figs. 5 and 6, red and blue patches are related to cyclones and anticyclones, respectively. Note that the blue patches south of the northern boundary of the plume are caused by bottom friction and are not related to the eddies. At section 3, cyclones and anticyclones alternate regularly in time, with anticyclones being weaker (note the color bar) and of shorter duration than cyclones (Fig. $7 b)$. Also, the centers of anticyclones are located farther upslope than those of cyclones along section 3. However, they later move downslope across the isobaths, whereas cyclones travel along the 800-m isobath (see Fig. 6).

Cyclones are associated with wider plumes and larger volume transports (Fig. 7b). The position of the upslope end of the plume is approximately steady, whereas its downslope edge significantly oscillates across the slope, with a distance as large as $30 \mathrm{~km}$. This is a manifestation of the potential energy release due to baroclinic instability near the lower edge of the plume (Swaters 1991; Reszka et al. 2002) and will be examined in the next section. Meanwhile, the tracer-weighted mean position of the plume core (gray lines in Fig. 7), here defined as (Riemenschneider and Legg 2007)

$$
Y(t)=\frac{\int y \tau(y, z, t) d y d z}{\int \tau(y, z, t) d y d z},
$$

is also correlated with the passing eddies; the core is located downslope during cyclones, whereas anticyclones are regularly associated with mean upslope excursion of the plume.

For the plume-induced eddy features at the surface, cyclones and anticyclones are no less pronounced than those at the bottom (Fig. 7a). They are spatially and temporally more coherent and have similar relative potential vorticity magnitude and duration.

Foldvik et al. (1988) and Darelius et al. (2011) showed that pairs of cyclonic and anticyclonic eddies moving westward in the Northern Hemisphere are recorded as clockwise $(\mathrm{CW})$ motions at a mooring on the right side of the eddy center (looking downstream), as counterclockwise $(\mathrm{CCW})$ motions on the left side, and as rectilinear motions in the core [see the sketch in Fig. 15 of Darelius et al. (2011)], regardless of the polarity of the passing eddies. Such a scenario is helpful for delineating eddy properties, especially for identifying the core and lateral extent of the propagating eddies. Figure 8 shows the time evolution of the surface and the bottom velocity vectors at upslope $(y=-4 \mathrm{~km})$, middle $(y=-16 \mathrm{~km})$, and downslope $(y=-28 \mathrm{~km})$ of the eddy centers at section 3 . The mean velocity vectors are marked on the right. Also shown is the temporal variation of the density anomaly at $100 \mathrm{mab}$, with blue colors indicating a colder and denser plume. Although distorted by the large 


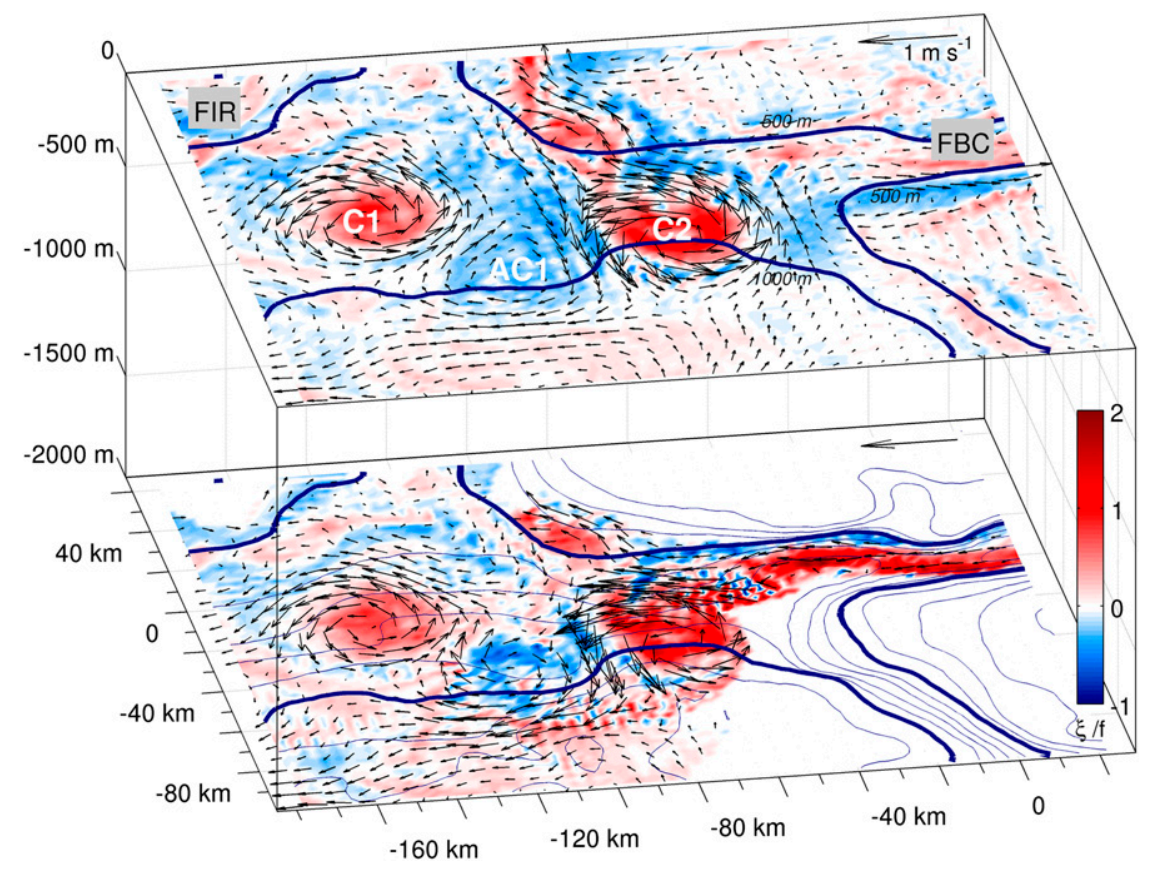

FIG. 6. As in Fig. 5, but at $t=92.33$ days.

westward bottom current, the rotation of the velocity vectors can be clearly seen upslope $(\mathrm{CW})$ and downslope $(\mathrm{CCW})$ of the eddy center, whereas in the center $(y=-16 \mathrm{~km})$, an overall rectilinear feature is seen, but $\mathrm{CW}$ and $\mathrm{CCW}$ motions are weak due to the slight meridional migration of the eddy center (see Fig. 7). The location of $y=-16 \mathrm{~km}$ corresponds to the depth of $\sim 800 \mathrm{~m}$, which can be diagnosed as the position of the eddy center. The above properties are consistent with mooring observations reported by Darelius et al. (2011). For the surface vectors, the mean velocities are small and the rotating velocity vectors become more apparent. Likewise, $\mathrm{CW}$, rectilinear, and CCW motions occur at $y=-4,-16$, and $-28 \mathrm{~km}$, respectively.

Comparing Figs. 7 and 8 , it can be readily seen that cyclones are associated with denser, colder overflow water, and anticyclones are associated with lighter, warmer water. This can also be inferred from the velocity vectors; when the center of cyclones passes by, westward (eastward) velocities are induced on the right (left)-hand side, whereas in the center itself the velocity switches from southward to northward. Correlation of cyclones (anticyclones) with larger (smaller) volume transport and colder (warmer) bottom water is sought from field observations. Figure 9 shows a 15-day time series of $\xi / f$, volume transport, and temperature measured in June 2012. The value of $\xi$ is estimated from the mooring triangle S2/S3/M1 at $100 \mathrm{mab}$, and volume transport and temperature (100 mab) are from S2 (see
Fig. 1 for locations). S2 is situated at $\sim 800$-m depth and is approximately in the path of eddy centers. The counterphase of $\xi$ with volume transport and temperature in Fig. 9 is striking (the correlation between $\xi$ and volume transport past $\mathrm{S} 2$ is -0.83 and between $\xi$ and temperature at S2 is -0.82), supporting the modelsimulated correlation of vorticity with volume transport and temperature of the plume.

In summary, the above discussions illustrate that the generated eddies significantly affect the plume characteristics and dynamics downstream of the sill. Cyclones are associated with a larger plume thickness and width, larger volume transport, colder and denser water, and a plume core located farther downslope. The opposite is true for anticyclones.

Tracing the eddies along the slope, it is found that cyclones migrate westward along the slope and turn sharply southward east of Iceland, following topographic contours, after which they propagate southward (with a speed of $\sim 0.23 \mathrm{~m} \mathrm{~s}^{-1}$ ) banking off the Icelandic slope down to the southern boundary of the model domain. In contrast, anticyclones gradually weaken and barely reach the Icelandic slope. Figure 10a shows a snapshot of the bottom-averaged $\xi / f$ and the velocity field east of Iceland ( $t=102$ days). There is one cyclone approaching section 5 and one cyclone passing by section 6 , and in between the two sections there are some cyclonic plume features, but no clear anticyclonic signatures are seen. The volume transport across section 5 

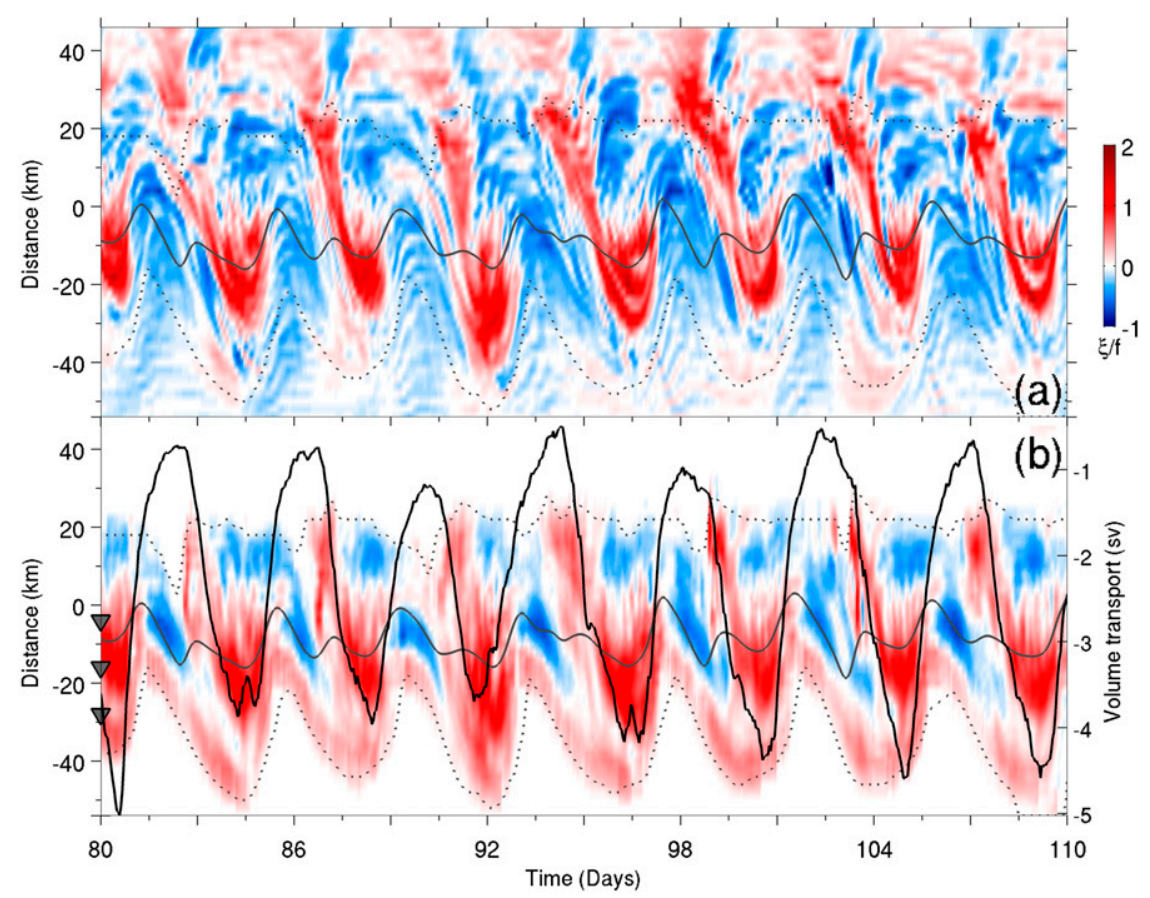

FIG. 7. Hövmoller diagram of the scaled relative vorticity ( $\xi / f$; color) along section 3 for the (a) surface and the (b) plume average. The black line in panel (b) denotes the time series of the overflow volume transport across section 3 (with $y$ axis on the right). Two gray lines in both panels denote the time evolution of the tracer-weighted mean position of the plume, whereas the dotted lines define the lateral boundaries of the plume. The three triangles on the left correspond to the upper, (approximately) central, and lower parts of the translating eddies, respectively, and will be used in Fig. 8.

also exhibits strong variability, but no distinct period can be inferred. The mean volume transport across section 5 reaches $3 \mathrm{~Sv}$ (Fig. 10b), which is $33 \%$ greater than that across section 4 . The increase of the mean volume transport from section 5 to section 6 is not obvious because the plume near section 6 has not reached a steady state in the last 30 days of the model output, and an average of the volume transport in the last 10 days yields a similar value of $3 \mathrm{~Sv}$. Similar to section 3 , the passage of cyclones is associated with large volume transport at section 6 (see the lower circle in Fig. 10b), and the eddies are also vertically aligned and barotropic (figure not shown).

\section{Generation mechanism: Baroclinic instability}

There are two main processes responsible for the instability of a bottom-attached overflow plume and the subsequent generation of mesoscale eddies. One is due to the bottom friction-induced vortex stretching of the captured overlying ambient water, which is accompanied by the generation of cyclones in the upper layer. The associated dynamical processes were examined in the laboratory by Lane-Serff and Baines (1998), who found that Ekman drainage is important in stretching the water column, and the properties of the generated eddies depend largely on a stretching parameter (only with sufficient stretching can eddies be generated).

The other process is baroclinic instability, which is very common in geophysical fluids and has been the subject of much research on rotating hydraulics (e.g., Smith 1976; Swaters 1991; Reszka et al. 2002). Baroclinic instability occurs due to the release of mean potential energy that is stored in the density field. A necessary condition for baroclinic instability is that the lateral gradient of potential vorticity changes sign somewhere in the vertical plane (Gill et al. 1974). For a bottomattached plume flowing on a slope, baroclinic instability tends to develop near the downslope edge due to the steeper inclination of isopycnals, which can cause crossslope spatial asymmetries of the perturbed plume (Swaters 1991; Choboter and Swaters 2000). The induced perturbations are often manifested as downslope-propagating subplumes that are detached from the main stream (Jiang and Garwood 1995; Reszka et al. 2002). Reszka et al. (2002) also showed the alternating appearance of eddies of both signs in the upper layer, in a similar manner to the primitive equation modeling of Jungclaus et al. (2001). 


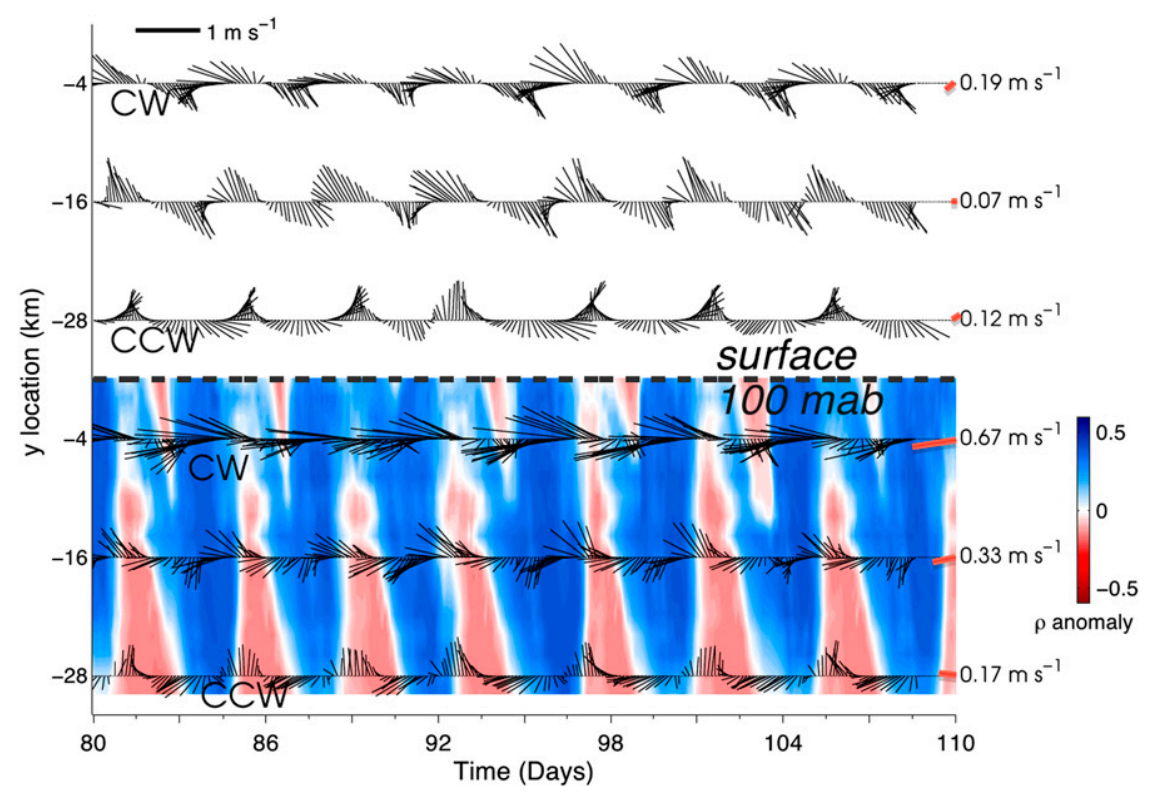

FIG. 8. Surface and bottom (100 mab) velocity vectors showing the eddy-associated rotating features of the overflow at three locations along section 3: $y=-4,-16$, and $-28 \mathrm{~km}$, corresponding to the upper, (approximately) central, and lower parts of the translating eddies, respectively (see the triangles in Fig. 7 for their positions). The rightmost vectors of the series are the 30-day mean. The underlying color plot is the temporal variation of density anomaly relative to $1027.65 \mathrm{~kg} \mathrm{~m}^{-3}$. Therefore, the blue (red) color corresponds to denser (lighter) and colder (warmer) water.

Vortex stretching is also involved in baroclinic instability, but in a manner different from that induced by the Ekman drainage due to bottom friction. For a baroclinically unstable overflow plume propagating on a slope, the descent and retreat of the wavy plume leads to the stretching and squeezing of the water column and thus contributes to the eddy formation.

In the simulation presented in the previous section, the modeled results bear close resemblance to baroclinic instability, for example, the spatial asymmetry of the flow at the upper and lower edges and the alternating appearance of cyclones and anticyclones. Below, a linear instability analysis for the FBC overflow is performed and a calculation of the eddy heat flux (EHF) and energy conversion rate are conducted to further verify the prevalence of baroclinic instability at this region in a qualitative and quantitative way.

\section{a. Linear instability analysis}

Here the two-layer linearized baroclinic model of Reszka et al. (2002) is employed to perform a linear instability analysis. The model is based on Swaters (1991) model, but it incorporates a continuously stratified upper layer and allows for a more accurate representation of overflows on a linear slope. Important input parameters of the model include: plume thickness and width, total fluid depth, upper- and lower-layer density anomalies, upper-layer stratification, and topographic slope. The instability is most sensitive to the plume thickness; the maximum growth rate and the most unstable along-channel wavenumber both increase with increasing plume thickness.

In applying the model to the $\mathrm{FBC}$, the plume properties along section 3 (Fig. 2c) are used for the model input. This section exhibits a nearly linear slope and the instabilities are at the nascent stage there. A density profile at the core of the plume is used to estimate the upper- and lower-layer thicknesses and the density anomaly for a two-layer configuration. Given the sensitivity of the model behavior to the input parameters, caution must be taken when approximating the MITgcm output with a two-layer profile. To that end, the continuous profile from the model is fitted to a two-layer profile using least squares minimization. The input parameters and their values for section 3 are: plume thickness $(160 \mathrm{~m})$, plume width $(60 \mathrm{~km})$, total depth $(900 \mathrm{~m})$, density anomaly $\left(0.41 \mathrm{~kg} \mathrm{~m}^{-3}\right)$, stratification $\left(8.12 \times 10^{-7} \mathrm{~s}^{-2}\right)$, and slope (0.01).

With the input parameters above, the predicted wavelength and period for the most unstable alongchannel wave mode are $75 \mathrm{~km}$ and 3.4 days, respectively. There is reasonable agreement with the MITgcmmodeled results of $\sim 100 \mathrm{~km}$ and $\sim 4$ days. Note that compared to the rest of the variables the instability 


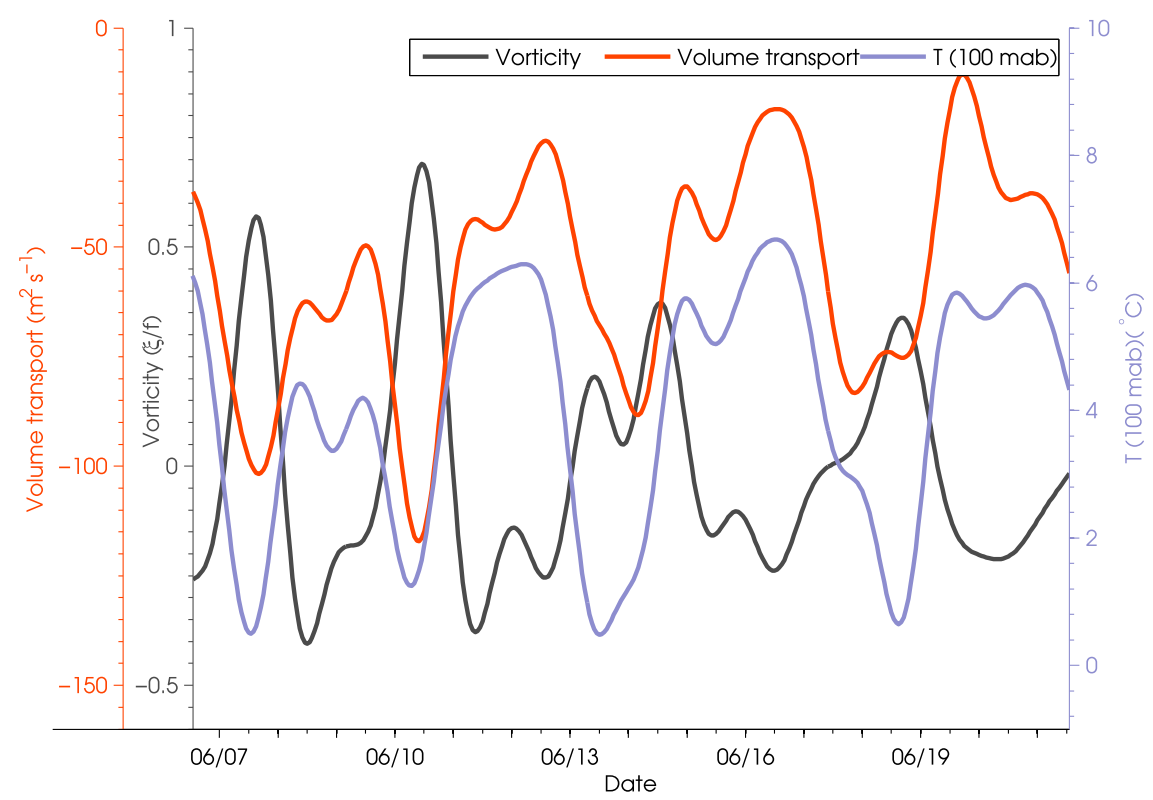

FIG. 9. Observed time series of scaled relative vorticity $\xi / f$ at 100 mab (black curve), volume transport per unit width $\left(\mathrm{m}^{2} \mathrm{~s}^{-1}\right.$; red curve), and temperature (100 mab; blue curve). The relative vorticity is estimated from the mooring triangle S2/S3/M1. Volume transport and temperature data are from S2. The 15-day time series shown was obtained in June 2012.

analysis is sensitive to the plume thickness in this region that shows large variation due to the mesoscale variability. For example, increasing and decreasing the plume thickness by $20 \mathrm{~m}$ changes the predicted periods of the most unstable mode to 2.9 and 3.9 days, respectively. Nevertheless, this does not jeopardize the consistency of the MITgcm simulation with the analytical baroclinic model, which supports the presence of baroclinic instability in this region. On the other hand, removing the upper-layer stratification increases the period from 3.4 to 5.4 days, similar to the conclusion of Reszka et al. (2002).

\section{b. Eddy heat flux}

For baroclinically unstable flows, loss of available potential energy leads to a downgradient lateral transport of heat. At the FBC, this corresponds to an EHF directed to the right of the plume (looking downstream). The EHF $\overline{\mathbf{u}^{\prime} T^{\prime}}$, where $\mathbf{u}^{\prime}=(u, v)$ and $T^{\prime}$ are velocity and temperature fluctuations (deviation from the time mean) and an overbar denotes a time mean, indicates a temporal correlation between $\mathbf{u}^{\prime}$ and $T^{\prime}$ induced by the eddies. Below, the distribution of the EHF downstream of the FBC is calculated to further confirm the presence of baroclinic instability in this region and to quantify eddy energetics.

It is known that the EHF is composed of a rotational (nondivergent) component and a residual divergent component (Marshall and Shutts 1981; Cronin and Watts 1996; Bishop et al. 2013):

$$
\overline{\mathbf{u}^{\prime} T^{\prime}}={\overline{\mathbf{u}^{\prime} T^{\prime}}}^{\text {div }}+{\overline{\mathbf{u}^{\prime} T^{\prime}}}^{\text {rot }} \text {. }
$$

The rotational EHF plays no dynamical role in transporting heat flux but can mask the dynamically important divergent EHF, which advects heat across the front and lowers the available potential energy. One method to estimate the divergent EHF was developed by Marshall and Shutts (1981) who showed that, given the prerequisite that the mean velocity field approximately follows mean temperature contours, that is, $\overline{\mathbf{u}} \cdot \nabla \bar{T} \approx 0$, the rotational EHF is then associated with the temperature variance:

$$
{\overline{\mathbf{u}^{\prime} T^{\prime}}}^{\mathrm{rot}}=\gamma \hat{\mathbf{k}} \times \nabla{\overline{T^{\prime 2}}}
$$

where $\hat{\mathbf{k}}$ is the unit vector directed upward, and

$$
\gamma=\frac{1}{2} \frac{d \bar{\Psi}}{d \bar{T}}
$$

Here $\bar{\Psi}$ is the mean geostrophic streamfunction of the flow $\left(\mathrm{m}^{2} \mathrm{~s}^{-2}\right)$. For $\overline{\mathbf{u}} \cdot \nabla \bar{T}=0, \bar{\Psi}=\bar{\Psi}(\bar{T})$, and $d \bar{\Psi} / d \bar{T}$ can be empirically estimated from the scatterplot of $\bar{\Psi}$ and $\bar{T}$ at multiple locations. Therefore a constant $\gamma$ can be obtained as the slope from a linear regression. Then the divergent EHF can be estimated using Eqs. (2) and (3): 


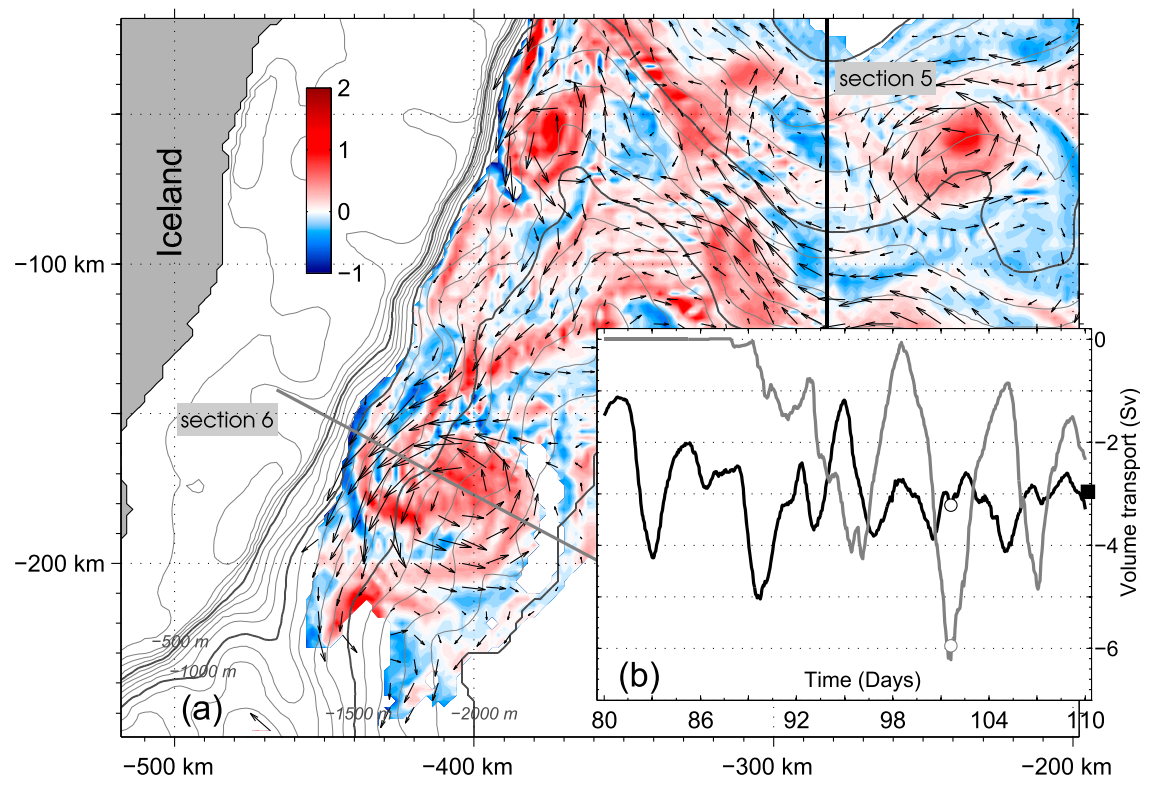

FIG. 10. (a) Bottom-averaged scaled relative vorticity ( $\xi / f$; color) and velocity field (arrows) at $t=102$ days east of Iceland. The gray contours are isobaths with an interval of $100 \mathrm{~m}$ (thick contours indicate the 500-, 1000-, 1500-, and 2000-m isobaths). The black line and the gray line denote the locations of section 5 and section 6 , respectively. (b) Time series of the overflow volume transport across section 5 (black) and section 6 (gray). The square on the right denotes the 30-day mean value for section 5. The two circles indicate the moment of panel (a). Note that the zero value in the first few days for section 6 is because the main plume has not reached the section.

$$
{\overline{\mathbf{u}^{\prime} T^{\prime}}}^{\operatorname{div}}=\overline{\mathbf{u}^{\prime} T^{\prime}}-\gamma \hat{\mathbf{k}} \times \nabla \overline{T^{\prime 2}} .
$$

Note that the divergent EHF is estimated as the residual of the rotational EHF. It is not guaranteed to be purely divergent and can also contain a rotational component (Bishop et al. 2013).

In the region downstream of the $\mathrm{FBC}$, the condition of $\overline{\mathbf{u}} \cdot \nabla \bar{T} \approx 0$ is satisfied at 100 mab (figure not shown), and the regression of $\bar{\Psi}$ against $\bar{T}$ in the plume-occupied locations yields $\gamma=0.49$. Then the rotational and divergent EHFs are calculated according to Eqs. (3) and (5), using the time mean over the last 30 days (between 80 and 110 days). A caveat is that the 30 -day duration is not long enough to allow for a robust statistical analysis of the EHF. This is a compromise as longer runs would result in reflections of the plume from the southern boundary. However, as long as the model has reached a steady state near the FBC and the eddies show up regularly, the 30-day analysis (including 7-8 events of pairs of cyclone and anticyclone) is expected to yield similar results to those of longer runs. Figure 11 shows the decomposition of the total EHF at 100 mab for the region downstream of the $\mathrm{FBC}$, superimposed on the temperature variance. The total EHF is insignificant before $x=-40 \mathrm{~km}$; then it displays smooth, upslope vectors between the 500- and 1200-m isobaths until $x=$ $-100 \mathrm{~km}$ where it nearly vanishes. After decomposing the total EHF into its rotational and divergent components, a different scenario appears. The rotational EHF anticyclonically follows the temperature variance [as implied by Eq. (3)], being most pronounced in an elongated region starting from $x=-15 \mathrm{~km}$ near the sill down to $1200-\mathrm{m}$ depth and a secondary (less pronounced) region just above of it. These two regions with high temperature variance are correlated with the two mean plume paths shown in Fig. 2, highlighting the role of eddies in creating such variance along the mean path. Meanwhile, the dynamically important divergent EHF is comparable in magnitude with its rotational counterpart, and has a more complex but intriguing structure. The vectors are directed downslope between the sill and $x=-40 \mathrm{~km}$, cancelling the rotational component in this area. The eddy activity upstream of $x=-40 \mathrm{~km}$ is weak (Fig. 4), which results in the small covariance between $\mathbf{u}^{\prime}$ and $T^{\prime}$ that leads to a weak total EHF (Fig. 11a). In this region, the plume is more concentrated along the mean path, hence $\overline{T^{\prime 2}}$ decreases sharply across the right edge of the plume, leading to a strong eastward rotational EHF [from Eq. (3), the $x$ component of the rotational EHF is $\left.-\gamma \partial \overline{T^{2}} / \partial y\right]$. Since the total EHF is small, this is balanced 


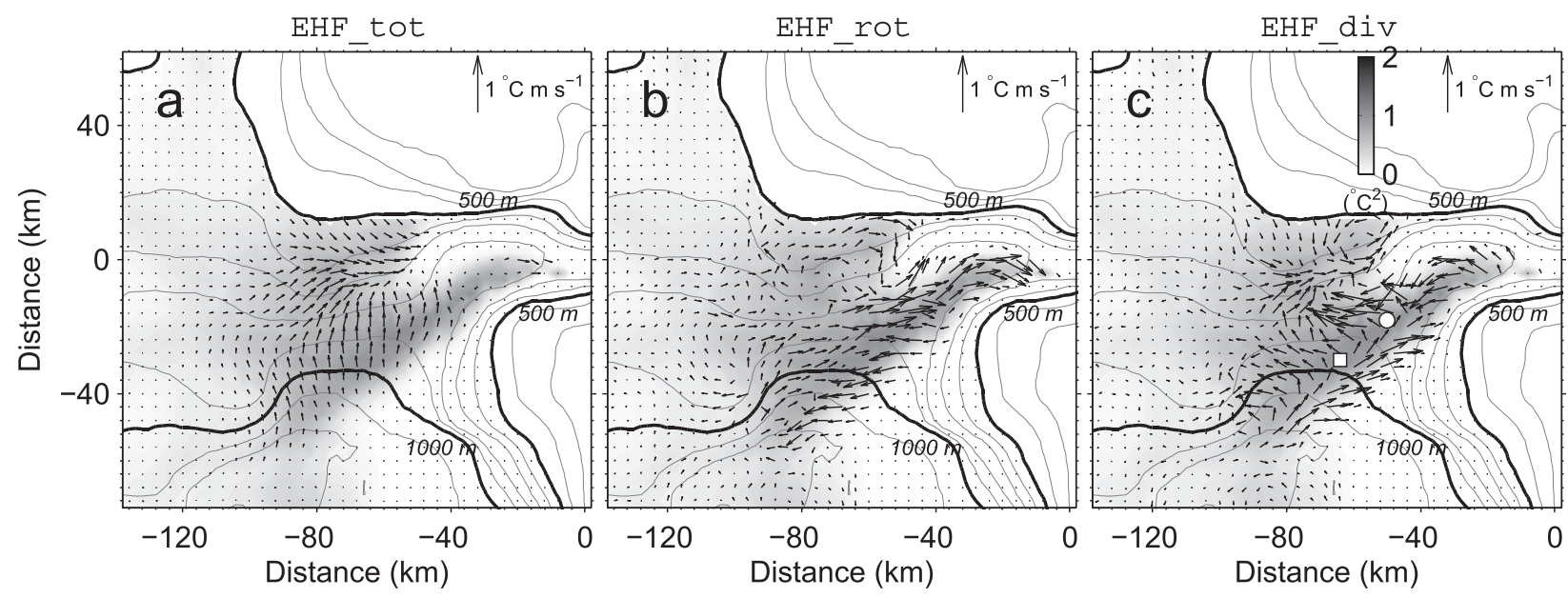

FIG. 11. Model-diagnosed (a) total, (b) rotational, and (c) divergent EHF $\left({ }^{\circ} \mathrm{Cm} \mathrm{s}^{-1}\right.$; arrows) superimposed on the temperature variance $\left({ }^{\circ} \mathrm{C}^{2}\right.$; gray color). They are calculated at $100 \mathrm{mab}$. The square and the circle denote two positions used in Fig. 12.

by a westward divergent EHF. On the other hand, after $x=-40 \mathrm{~km}$, where the mean plume flows along the depth contours and eddies have developed, the EHF vectors have a strong rightward component that is directed upslope. This component is responsible for the cross-plume heat exchange and is correlated with the strong eddy activities due to baroclinic instability. The overall distribution of the divergent EHF does not differ from that of the total EHF; they both exhibit rightward heat flux, with the former aligned more perpendicular to the mean plume path. Moreover, at the deeper edge of the mean plume an upslope transport with a slight leftward transport is exhibited. Note that the magnitude of the calculated EHF (maximum $\sim 0.8^{\circ} \mathrm{Cm} \mathrm{s}^{-1}$ ) agrees well with observations reported by Darelius et al. (2011) and is comparable with that observed in the Gulf Stream (Cronin and Watts 1996).

Figure 12 shows the vertical structure of the divergent EHF at two locations along the mean plume path (see Fig. 11c for their positions). The left profile is close to section 3 and is located on the slope. The two profiles are representative of the distribution of the divergent EHF in the vertical in this region, and they are also associated with a high baroclinic conversion rate as will be shown in the next subsection. In the profiles the divergent EHF has a northward (upslope) component in the vertical, and a westward component near the bottom that progressively turns eastward farther up. For the profile on the slope near section 3 (the left one in Fig. 12), the magnitude of the divergent EHF reaches a maximum near $\sim 120$ mab. As Bishop et al. (2013) reasoned, the depth where the maximum divergent EHF takes place corresponds to where the mean lateral gradient of the quasigeostrophic potential vorticity changes sign in the vertical, which is a necessary condition for baroclinic instability (Gill et al. 1974). Calculation of the lateral gradient of the potential vorticity on the slope shows that it indeed changes sign near the maximum divergent EHF. For the right profile in Fig. 12 when the plume is descending, the maximum divergent EHF is confined to the bottom and gradually diminishes upward.

\section{c. Baroclinic conversion rate}

Since only the horizontally divergent EHF is associated with heat advection, a dynamical baroclinic conversion rate (BC) can be defined as the product of EHF with $\nabla \bar{T}$, which measures the energy conversion from mean potential energy to eddy potential energy (Cronin and Watts 1996; Bishop et al. 2013):

$$
\mathrm{BC}=-\frac{\alpha_{0} g}{\theta_{z}} \overline{\mathbf{u}^{\prime} T^{\prime}} \mathrm{div} \cdot \nabla \bar{T}
$$

where $\alpha_{0}$ is an effective thermal expansion coefficient $\left(\sim 10^{-4}{ }^{\circ} \mathrm{C}^{-1}\right), \theta(z)$ is the depth-dependent background potential temperature, and the subscript $z$ denotes the vertical gradient.

Figure 13 shows the distribution of the divergent EHF superimposed on the dynamical BC. The strongest conversion occurs along the mean path of the plume before bifurcation and has values of $\sim 0.6 \times 10^{-5} \mathrm{~m}^{2} \mathrm{~s}^{-3}$. Two positions with strong conversion in Fig. 13 have vertical profiles of the divergent EHF shown in Fig. 12. The calculated baroclinic conversion rate here is a few times larger than that observed in the Gulf Stream (Cronin and Watts 1996), suggesting strong mean-to-eddy energy conversion in this region. Some patches with negative values are also visible on the lower edge of the upper branch of the mean flow after bifurcation, but their magnitude and area are much smaller than the region with positive conversion rate. 


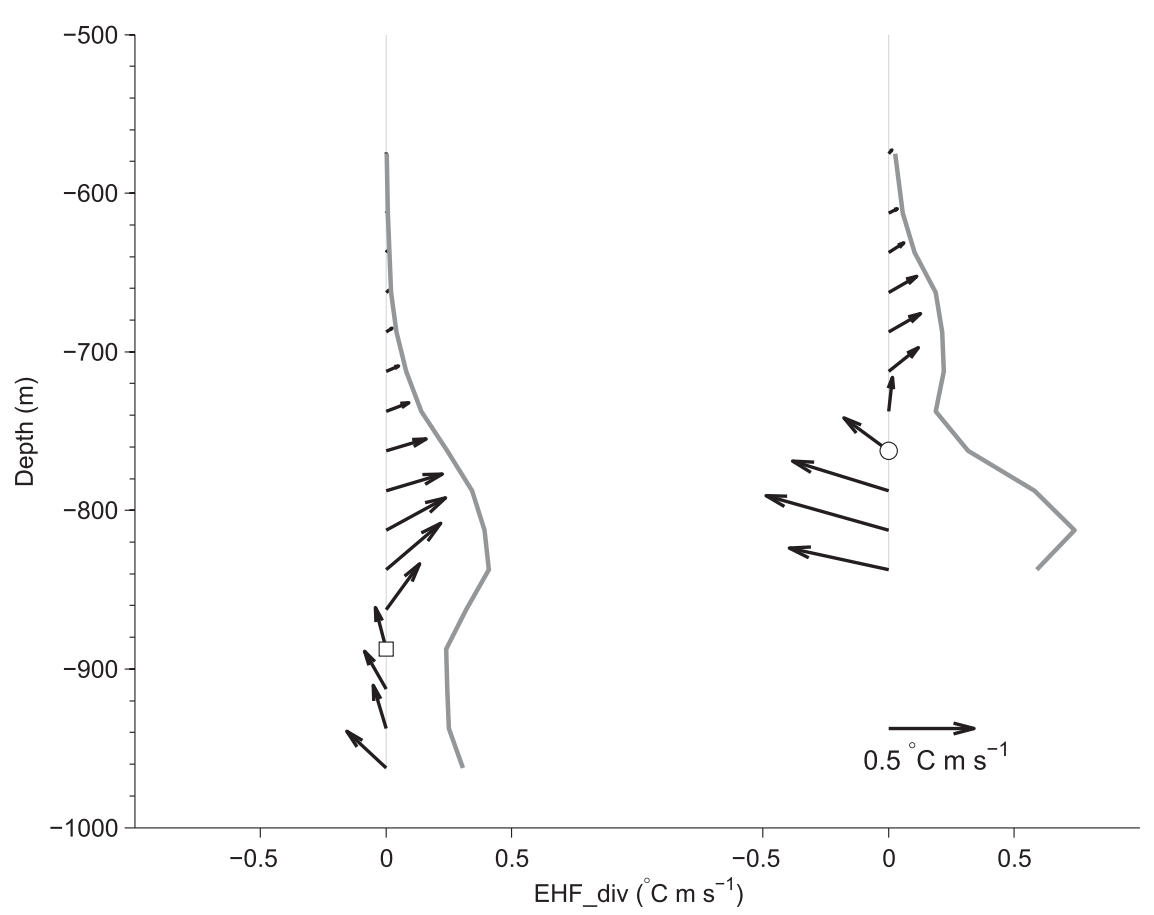

FIG. 12. Vertical profiles of the divergent EHF (arrows) at two positions along the mean path of the plume (see the square and the circle in Fig. 11c for the locations). The two gray lines denote the magnitudes of the divergent EHF, with the scale on the $x$ axis. The EHF located at the square and the circle (100 mab) corresponds exactly to those in Fig. 11c.

\section{Discussion}

\section{a. Baroclinic instability of the FBC overflow}

The evidence presented in section 6 is in support of the prevalence of baroclinic instability in the FBC region, for example, the cross-frontal asymmetry of the plume with much larger variation at the downslope edge, the alternation of cyclones and anticyclones, the agreement with a linear analytical model, a rightwarddirected divergent EHF, and a region with strong baroclinic conversion rate. The magnitudes of the EHF and the energy conversion are quantified and their distribution are also mapped downstream of the FBC sill.

Darelius et al. (2011) discussed the dominant generation mechanisms of mesoscale eddies at the FBC region. They ruled out the possibility of vortex stretching due to bottom friction by performing a scaling estimation of Lane-Serff and Baines (1998)'s laboratory study. The estimate agrees with their observations in periodicity, but there is a disparity with length scale and speed. Darelius et al. (2011) also discarded baroclinic instability as the origin of the oscillations on two grounds: 1) observations indicated a downward phase velocity, and 2) the mean slope of the isotherms was approximately parallel to the bottom. A closer inspection of their Fig. 6 suggests that the mean $3^{\circ} \mathrm{C}$ isotherm (representative of the isopycnal delineating the overflow plume) slopes either in the opposite or the same direction as the isobaths, reminiscent of case 1 and case 3 of Pavec et al. (2005); both cases are unstable modes for quasigeostrophic theory. The first point arises from a misinterpretation of the relative phase profiles presented in their Fig. 11 where the vertical distribution of phase profiles decreases with height above bottom. Darelius et al. (2011) interpreted this observation as being inconsistent with the vertical structure expected from baroclinic instability. When the $x$ axis opposes the direction of the phase propagation of the unstable wave, as is the case in their choice of coordinate system (and also in this study), the phase is expected to decrease with height (see Gill et al. 1974), consistent with the observations. Furthermore, a vertical phase distribution decreasing with height above bottom means that the unstable wave has a positive slope in the $x-z$ plane; that is, it leans against mean FBC overflow current. This is consistent with the baroclinic instability, both in our model results and in the observations of Darelius et al. (2011). Darelius et al. (2011) interpreted their observations in terms of topographic Rossby waves. As also noted by Spall and Price (1998), cyclones propagate along the slope as topographic Rossby waves, consistent with the baroclinically unstable waves that arise in the analytical model of a dense gravity current on a slope (Swaters 1991; 


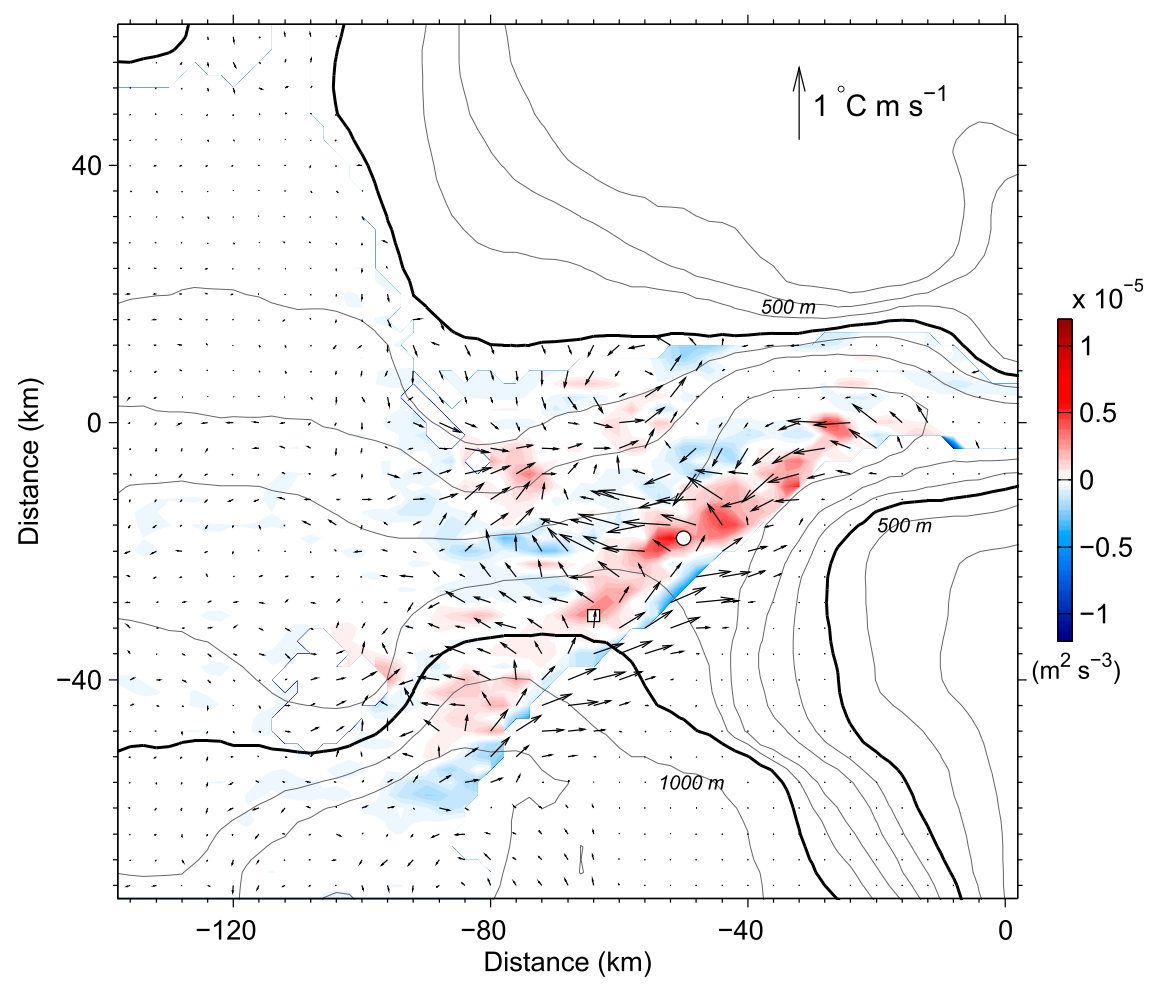

FIG. 13. Decomposed divergent EHF $\left({ }^{\circ} \mathrm{Cm} \mathrm{s}^{-1}\right.$; arrows) superimposed on the dynamical BC contours $\left(\mathrm{m}^{2} \mathrm{~s}^{-3}\right)$ calculated at $100 \mathrm{mab}$. The square and the circle in the figure where strong conversion occurs correspond to those in Figs. 11 and 12. Note that the region where the mean plume thickness is smaller than $100 \mathrm{~m}$ has been excluded for the calculation of $\mathrm{BC}$.

Reszka et al. 2002). In this aspect, Darelius et al. (2011)'s observations of topographic Rossby waves are not inconsistent with the present results.

As also discussed in the beginning of section 6 , it should be addressed that vortex stretching and baroclinic instability are not mutually exclusive, as the former process is part of the latter one. The slump of the dense plume from the top of the sill must induce an abrupt change of the thickness of the water column and thus stretches the upper layer and accounts for some of the eddy activities. However, how much role it plays in the subsequent eddy formation is unclear and is difficult to evaluate. An additional complication arises from the presence of oscillations upstream of and above the sill and how this has an impact on the destabilization of the plume is also open to question. Ezer (2006)'s idealized setup of the FBC overflow with a direct westward inflow upstream of the sill does not produce any oscillations above the sill but yields similar eddy features to the present study, with only quantitative differences, which implies that the oscillations above the FBC sill do not play a crucial role in the formation of eddies downstream, but can certainly modify their properties.

\section{b. Sensitivity to forcing}

Observations have indicated seasonal variations of volume transport above the sill with a maximum in summer and with an amplitude of $0.22 \mathrm{~Sv}$, which is about $10 \%$ of the mean volume transport (Hansen and Østerhus 2007). The change of the magnitude of the inflow must have some influence on the overflow behavior at the FBC region. Hence, to examine the effect of inflow volume transport on the downstream variability and eddy activity, four additional sets of sensitivity experiments with larger/ smaller inflow velocities were performed. The inflow velocities are $0.1,0.25,2$, and 5 times that in the reference experiment, whereas the inflow thickness in the northern boundary is unaltered. The outflow is also increased/ decreased accordingly for the balance of volume. The four experiments plus the reference one are labeled, according to the increasing inflow strength, as E1, E2, E3 (reference), E4, and E5. The spinup time for E1 and E2 is longer to ensure that the model reaches a steady state.

For the five experiments, a comparison of plume structures along section 1 and section 3 is shown in Fig. 14, and the associated volume transport across the two sections is shown in Fig. 15a. For the analysis here, 


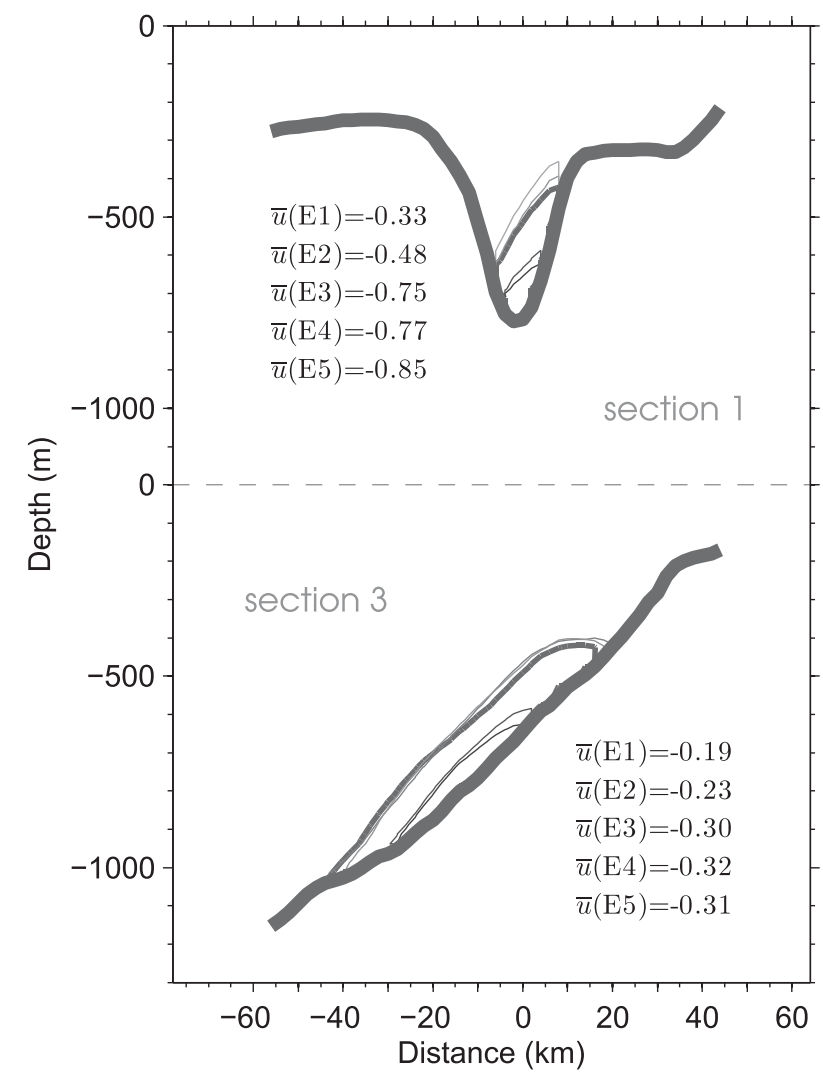

FIG. 14. A comparison of the plume interfaces (here defined as $\rho=1027.65 \mathrm{~kg} \mathrm{~m}^{-3}$ ) inferred from experiments E1 to E5, with fading colors from E1 to E5. The E3 (reference experiment) is marked by bold lines. The upper and lower profiles are for sections 1 and 3 , respectively. The labeled values of $\bar{u}$ are the plume-mean velocities $\left(\mathrm{m} \mathrm{s}^{-1}\right)$ for the five experiments.

the passive tracer threshold $(\tau=0.1)$ is discarded, as it becomes problematic in comparing plume profiles for the five experiments, as a result of varying the amount of dilution in the upstream basin caused by different inflow velocities. The results become sensitive to minor changes in the arbitrary tracer threshold of 0.1. Rather, the isopycnal $\rho=1027.65 \mathrm{~kg} \mathrm{~m}^{-3}$ is chosen to define the plume interface at sections 1 and 3 (Mauritzen et al. 2005). Note that in the reference experiment, the plume interface defined by $\rho=1027.65 \mathrm{~kg} \mathrm{~m}^{-3}$ is similar to that defined by $\tau=0.1$ at the two sections, and it also delineates the plume robustly for the other runs. Figure 14 shows that the plume thickness and the plume-mean velocity both increase with increasing forcing, as both are evident at sections 1 and 3 . As a consequence of the change of plume thickness, characteristics of the most unstable along-slope mode vary, and the time interval between two consecutive eddies decreases with increasing plume thickness, as is implied by the linear model of Reszka et al. (2002) and in line with baroclinic instability. For example, the E5 case yields a period of $\sim 3.4$ days (compared to $\sim 4$ days in the reference experiment), whereas the $\mathrm{E} 1$ case has a period of $\sim 5.2$ days.

On the other hand, comparing profiles of E4 and E5 with that of E3, it is observed that enhancing the inflow only slightly increases the plume thickness and the mean velocity at section 1 , whereas at section 3 they are nearly identical. As a result, the inclination of the volume transport from E3 to E5 is much shallower than that from E1 to E3 (Fig. 15a).

Simulation results indicate that eddies are generated for all the experiments. Even for the case of E1, being smaller only in the magnitude of volume transport and having weaker eddy activity, alternating cyclones and anticyclones are clearly present (figure not shown). The mean eddy kinetic energy (EKE), $\overline{\mathrm{EKE}}=0.5 \overline{\left\langle u^{\prime 2}+v^{\prime 2}\right\rangle}$, where the overbar denotes the time mean, and the angle brackets denote the spatial mean within $x=[-100,0]$ and $y=[-50,50] \mathrm{km}$ for the whole water column, is calculated for the five experiments and shown in Fig. 15b as a function of volume transport across section 1. A monotonic, nearly linear increase of $\overline{\mathrm{EKE}}$ with the increasing volume transport across the sill is seen, indicating enhanced eddy activity from E1 to E5. Also shown in Fig. 15b is the rate of change of background potential energy $\left(E_{b t}\right.$; where the subscript $t$ denotes the time derivative) averaged over the last 30 days for the five experiments. Changes in $E_{b}$ directly measure the potential energy changes resulting from diapycnal mixing (Winters et al. 1995; Ilicak et al. 2012); hence, it would be helpful to relate $E_{b}$ with mixing for the five experiments that have the same initial $E_{b}$ in the system. The calculation shows increased $E_{b t}$ from E1 to E5, indicating increased mixing, and a nearly linear trend exists for E1-E5 when plotting against the volume transport across the sill (Fig. 15b), similar to the variation of $\overline{E K E}$. The increased mixing is likely to be mainly caused by the enhanced eddy activity downstream of the FBC sill, as is tentatively elucidated by the correlation between $\overline{\mathrm{EKE}}$ and $E_{b}$ in Fig. 15b. However, this cannot be quantified with the present model, and further studies are needed to evaluate the eddy-induced mixing in this region.

\section{c. Approach}

In the current study, the $z$-level MITgcm is used with a semi-idealized inflow forcing in the northern boundary. In the future, realistic boundary forcing, together with the inclusion of wind and tides, is expected to be implemented and offer more accurate and faithful simulation of the FBC overflow dynamics. Moreover, the sufficiency of the model resolution also remains to be evaluated. Riemenschneider and Legg (2007) illustrated 

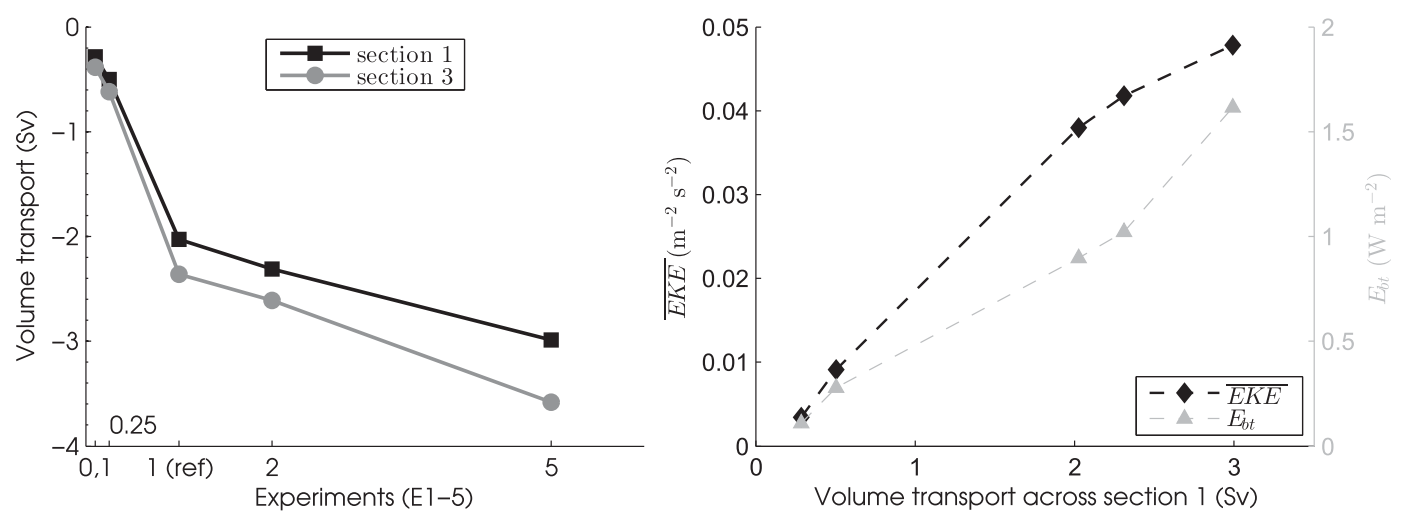

FIG. 15. (a) A comparison of mean volume transport across section 1 (black) and section 3 (gray) for experiments E1-E5. The $x$ axis is scaled with the magnitude of the inflow velocity, with E1 the smallest and E5 the largest. E3 is the reference experiment. (b) The mean eddy kinetic energy ( $\overline{\mathrm{EKE}}$; black) and the mean rate of change of background potential energy $\left(E_{b i}\right.$; gray) for experiments E1-E5. The $x$ axis is the volume transport across section 1 for the five experiments.

that coarse resolutions can degrade the simulation results, leading to a thicker and more sluggish plume. For the current study, an experiment with higher vertical resolution ( $10 \mathrm{~m}$ for the plume-covered region down the sill) shows no pronounced change in the plume dynamics compared to the reference experiment; however, the calculated entrainment coefficient $\alpha_{E}$ reduces by $22 \%$. This difference addresses the influence of resolution and has implications on regional simulations as well as the representation/parameterization of overflows in regional/ climate models.

\section{Conclusions}

Earlier studies have reported energetic mesoscale variability in the region downstream of the FBC sill in observations (Hansen and Østerhus 2000, 2007; Darelius et al. 2011, 2013) and recently in regional numerical models (Ezer 2006; Riemenschneider and Legg 2007; Seim et al. 2010). However, the physical mechanism of the unstable plume and the features of the induced mesoscale eddies have not been studied in detail. In this paper, the above issues are addressed using a regional simulation with realistic bathymetry and semi-idealized inflow forcing, aiming to further understand the underlying dynamics of the FBC overflow and to serve as a useful reference for correctly representing the overflow in climate modeling.

It is found that the volume transport of the overflow already exhibits oscillations at the sill. The flow gets increasingly oscillatory as the plume descends and propagates along the topographic contours. A distinct period of $\sim 4$ days is obtained for the temporal variation of the volume transport. Mesoscale eddies of both signs induced by the unstable plume emerge at about $40 \mathrm{~km}$ downstream of the sill, where the topography widens up and the curvature drastically decreases. Once generated, cyclones approximately follow the $800-\mathrm{m}$ isobath, whereas anticyclones, emerging side by side with cyclones, propagate downslope across the isobaths and are gradually diminished. Compared to the shorter duration of anticyclones, cyclones travel westward along the slope and are steered leftward when approaching Iceland; then they migrate southward banking on the Icelandic slope and finally reach the southern boundary. At the region downstream of the FBC, the eddies are shown to be vertically barotropic rather than being bottom intensified. Correlation of the eddies with plume properties indicates that cyclones are associated with a larger plume thickness and width, larger volume transport, colder and denser water, and a plume core located farther downslope, whereas the opposite occurs for anticyclones. The above statements are corroborated by field observations.

Several pieces of evidence for the generation mechanism of the unstable plume have been gathered, which all point to baroclinic instability. Larger oscillations are visible at the lower edge of the plume, resulting in a wavy fluctuation and causing spatial asymmetry across the plume, which are clear signs of release of potential energy stored in the mean plume. A linear instability analysis of Reszka et al. (2002)'s two-layer analytical baroclinic model yields a wavelength of $75 \mathrm{~km}$ and a period of 3.4 days for the most unstable along-slope mode, which agrees well with the simulated results of $\sim 100 \mathrm{~km}$ and $\sim 4$ days, respectively.

For the FBC overflow plume, baroclinic instability induces rightward EHF, of which only the divergent component is dynamically important in quantifying cross-frontal heat exchange. Model-derived distribution of the divergent EHF indicates a marked rightward 
upslope component from the location where the eddies emerge, signifying the nature of baroclinic instability and the importance of eddies in transporting heat. The calculated divergent EHF agrees with observations and is comparable in magnitude with that observed in the Gulf Stream. A map of mean-to-eddy potential energy conversion rate outlines an elongated area with strong conversion. This area follows the path of the mean plume, starting from near the sill down to 1200-m depth.

Four additional experiments with increased/ decreased inflow flux in the northern boundary were performed to assess its influence on the overflow dynamics. It is found that the experiments all exhibit pronounced mesoscale variability and eddy activity, but differ in, for example, plume profiles, volume transport, mean EKE, and $E_{b t}$. However, decreasing the inflow flux leads to a significant reduction of volume transport, mean EKE, and $E_{b t}$ down the sill, whereas increasing the inflow flux only slightly increases them. Both mean EKE and $E_{b t}$ are nearly linearly proportional to the volume transport across the sill.

In summary, this study assesses the mesoscale variability of the FBC overflow, and the occurrence of baroclinic instability is demonstrated. In the future, simulations with realistic boundary forcing and with the inclusion of wind and tides are expected to be performed. Mesoscale variability can affect the circulation and hydrographic patterns and should be accounted for in larger-scale models. This merits further studies, especially for the roles of eddies in diapycnal mixing and downslope volume transport.

Acknowledgments. We thank S. Legg for kindly providing the MITgcm code for forcing the model, which was used in Riemenschneider and Legg (2007). We also thank M. Reszka for offering the program of the twolayer linear model for the instability analysis at the FBC region. Comments from two anonymous reviewers are greatly appreciated. This study is funded by the Research Council of Norway through the project Faroe Bank Channel Overflow: Dynamics and Mixing.

\section{APPENDIX}

\section{Animation of the Plume Evolution}

Animations associated with this article are available in the supplemental material. The animations show, from two different angles of view, the three-dimensional evolution of the overflow plume in the final 15 days, with a time internal of $1 / 3$ day $(8 \mathrm{~h})$. The gray color denotes the plume interface defined by $\tau=0.1$. The four topographic contour lines are the 500-, 1000-, 1500-, and 2000-m isobaths, respectively. The abbreviations in the animations are the same as those in Fig. 1.

\section{REFERENCES}

Beaird, N. L., P. B. Rhines, and C. C. Eriksen, 2013: Overflow waters at the Iceland-Faroe Ridge observed in multiyear seaglider surveys. J. Phys. Oceanogr., 43, 2334-2351, doi:10.1175/ JPO-D-13-029.1.

Bishop, S. P., D. R. Watts, and K. A. Donohue, 2013: Divergent eddy heat flux in the Kuroshio Extension at $144^{\circ}-148^{\circ}$ E. Part I: Mean structure. J. Phys. Oceanogr., 43, 1533-1550, doi:10.1175/ JPO-D-12-0221.1.

Borenäs, K. M., and P. A. Lundberg, 1988: On the deep-water flow through the Faroe Bank Channel. J. Geophys. Res., 93, 12811292, doi:10.1029/JC093iC02p01281.

Cenedese, C., J. A. Whitehead, T. A. Ascarelli, and M. Ohiwa, 2004: A dense current flowing down a sloping bottom in a rotating fluid. J. Phys. Oceanogr., 34, 188-203, doi:10.1175/ 1520-0485(2004)034<0188:ADCFDA > 2.0.CO;2.

Choboter, P. F., and G. E. Swaters, 2000: On the baroclinic instability of axisymmetric rotating gravity currents with bottom slope. J. Fluid Mech., 408, 149-177, doi:10.1017/ S0022112099007661.

Cronin, M., and D. R. Watts, 1996: Eddy-mean flow interaction in the Gulf Stream at $68^{\circ} \mathrm{W}$. Part I: Eddy energetics. J. Phys. Oceanogr., 26, 2107-2131, doi:10.1175/1520-0485(1996) 026<2107:EFIITG > 2.0.CO;2.

Cuthbertson, A., D. Peter, N. Stashchuk, and V. Vlasenko, 2014: Model studies of dense water overflows in the Faroese Channels. Ocean Dyn., 64, 273-292, doi:10.1007/s10236-013-0685-2.

Darelius, E., I. Fer, and D. Quadfasel, 2011: Faroe Bank Channel overflow: Mesoscale variability. J. Phys. Oceanogr., 41, 21372154, doi:10.1175/JPO-D-11-035.1.

— J. E. Ullgren, and I. Fer, 2013: Observations of barotropic oscillations and their influence on mixing in the Faroe Bank Channel overflow region. J. Phys. Oceanogr., 43, 1525-1532, doi:10.1175/JPO-D-13-059.1.

Dickson, R. R., and J. Brown, 1994: The production of North Atlantic Deep Water: Sources, rates, and pathways. J. Geophys. Res., 99, 12319-12341, doi:10.1029/94JC00530.

Ezer, T., 2006: Topographic influence on overflow dynamics: Idealized numerical simulations and the Faroe Bank Channel overflow. J. Geophys. Res., 111, C02002, doi:10.1029/ 2005JC003195.

Fer, I., G. Voet, K. S. Seim, B. Rudels, and K. Latarius, 2010: Intense mixing of the Faroe Bank Channel overflow. Geophys. Res. Lett., 37, L02604, doi:10.1029/2009GL041924.

Foldvik, A., K. Aagaard, and T. Tørresen, 1988: On the velocity field of the East Greenland Current. Deep-Sea Res., 35A, 1335-1354, doi:10.1016/0198-0149(88)90086-6.

Geyer, F., S. Østerhus, B. Hansen, and D. Quadfasel, 2006: Observations of highly regular oscillations in the overflow plume downstream of the Faroe Bank Channel.J. Geophys. Res., 111, C12020, doi:10.1029/2006JC003693.

Gill, A. E., J. S. A. Green, and A. J. Simmons, 1974: Energy partition in the large-scale ocean circulation and the production of mid-ocean eddies. Deep-Sea Res. Oceanogr. Abstr., 21, 499508, doi:10.1016/0011-7471(74)90010-2.

Girton, J. B., L. J. Pratt, D. A. Sutherland, and J. F. Price, 2006: Is the Faroe Bank Channel overflow hydraulically controlled? J. Phys. Oceanogr., 36, 2340-2349, doi:10.1175/JPO2969.1. 
Griffiths, R. W., P. D. Killworth, and M. E. Stern, 1982: Ageostrophic instability of ocean currents. J. Fluid Mech., 117, 343-377, doi:10.1017/S0022112082001669.

Hansen, B., and S. Østerhus, 2000: North Atlantic-Nordic Seas exchanges. Prog. Oceanogr., 45, 109-208, doi:10.1016/ S0079-6611(99)00052-X.

— , and _ 2007: Faroe Bank Channel overflow 1995-2005. Prog. Oceanogr., 75, 817-856, doi:10.1016/j.pocean.2007.09.004.

Høyer, J. L., and D. Quadfasel, 2001: Detection of deep overflows with satellite altimetry. Geophys. Res. Lett., 28, 1611-1614, doi:10.1029/2000GL012549.

Ilicak, M., A. J. Adcroft, S. M. Griffies, and R. W. Hallberg, 2012: Spurious dianeutral mixing and the role of momentum closure. Ocean Modell., 45-46,37-58, doi:10.1016/j.ocemod.2011.10.003.

Jiang, L., and R. W. Garwood Jr., 1995: A numerical study of threedimensional dense bottom plumes on a southern ocean continental slope. J. Geophys. Res., 100, 18471-18488, doi:10.1029/ 95JC01512.

Jungclaus, J. H., J. Hauser, and R. H. Käse, 2001: Cyclogenesis in the Denmark Strait overflow plume. J. Phys. Oceanogr., 31, 3214-3229, doi:10.1175/1520-0485(2001)031<3214: CITDSO $>2.0 . \mathrm{CO} ; 2$.

Lane-Serff, G. F., and P. G. Baines, 1998: Eddy formation by dense flows on slopes in a rotating fluid. J. Fluid Mech., 363, 229-252, doi:10.1017/S0022112098001013.

Large, W. G., J. C. McWilliams, and S. C. Doney, 1994: Oceanic vertical mixing: A review and a model with a nonlocal boundary layer parameterization. Rev. Geophys., 32, 363-403, doi:10.1029/94RG01872.

Leith, C., 1996: Stochastic models of chaotic systems. Physica D, 98, 481-491, doi:10.1016/0167-2789(96)00107-8.

Marshall, J., and G. Shutts, 1981: A note on rotational and divergent eddy fluxes. J. Phys. Oceanogr., 11, 1677-1680, doi:10.1175/1520-0485(1981)011<1677:ANORAD>2.0.CO;2.

— - A. Adcroft, C. Hill, L. Perelman, and C. Heisey, 1997: A finite-volume, incompressible Navier Stokes model for studies of the ocean on parallel computers. J. Geophys. Res., 102, 5753-5766, doi:10.1029/96JC02775.

Mauritzen, C., J. F. Price, T. B. Sanford, and D. Torres, 2005 Circulation and mixing in the Faroese Channels. Deep-Sea Res. I, 52, 883-913, doi:10.1016/j.dsr.2004.11.018.

Pavec, M., X. Carton, and G. Swaters, 2005: Baroclinic instability of frontal geostrophic currents over a slope. J. Phys. Oceanogr., 35, 911-918, doi:10.1175/JPO2718.1.
Poulin, F. J., and G. E. Swaters, 1999: Sub-inertial dynamics of density-driven flows in a continuously stratified fluid on a sloping bottom. I. Model derivation and stability characteristics. Proc. Roy. Soc. London, A455, 2281-2304, doi:10.1098/ rspa.1999.0404.

Pratt, L. J., K. R. Helfrich, and D. Leen, 2008: On the stability of ocean overflows. J. Fluid Mech., 602, 241-266, doi:10.1017/ S0022112008000827.

Reszka, M. K., G. E. Swaters, and B. R. Sutherland, 2002: Instability of abyssal currents in a continuously stratified ocean with bottom topography. J. Phys. Oceanogr., 32, 3528-3550, doi:10.1175/1520-0485(2002)032<3528:IOACIA >2.0.CO;2.

Riemenschneider, U., and S. Legg, 2007: Regional simulations of the Faroe Bank Channel overflow in a level model. Ocean Modell., 17, 93-122, doi:10.1016/j.ocemod.2007.01.003.

Seim, K. S., and I. Fer, 2011: Mixing in the stratified interface of the Faroe Bank Channel overflow: The role of transverse circulation and internal waves. J. Geophys. Res., 116, C07022, doi:10.1029/2010JC006805.

- - - - and J. Berntsen, 2010: Regional simulations of the Faroe Bank Channel overflow using a sigma-coordinate ocean model. Ocean Modell., 35, 31-44, doi:10.1016/ j.ocemod.2010.06.002.

Smith, D. K., and D. Sandwell, 1997: Global sea floor topography from satellite altimetry and ship depth soundings. Science, 277, 1956-1962, doi:10.1126/science.277.5334.1956.

Smith, P. C., 1976: Baroclinic instability in Denmark Strait Overflow. J. Phys. Oceanogr., 6, 355-371, doi:10.1175/ 1520-0485(1976)006<0355:BIITDS $>2.0 . \mathrm{CO} ; 2$.

Spall, M. A., and J. F. Price, 1998: Mesoscale variability in Denmark Strait: The PV outflow hypothesis. J. Phys. Oceanogr., 28, 1598-1623, doi:10.1175/1520-0485(1998)028<1598: MVIDST>2.0.CO;2.

Swaters, G. E., 1991: On the baroclinic instability of cold-core coupled density fronts on a sloping continental shelf. J. Fluid Mech., 224, 361-382, doi:10.1017/S0022112091001799.

Tanaka, K., and K. Akitomo, 2001: Baroclinic instability of density current along a sloping bottom and the associated transport process. J. Geophys. Res., 106, 2621-2638, doi:10.1029/ $2000 \mathrm{JC} 000214$.

Winters, K. B., P. N. Lombard, J. J. Riley, and E. A. D'Asaro, 1995: Available potential energy and mixing in densitystratified fluids. J. Fluid Mech., 289, 115-128, doi:10.1017/ S002211209500125X 